Published in final edited form as:

J Hum Resour. 2019 ; 54(4): 825-856. doi:10.3368/jhr.54.4.1216-8401R1.

\title{
Does Access to Family Planning Increase Children's Opportunities? Evidence from the War on Poverty and the Early Years of Title $X$
}

\author{
Martha J. Bailey [Professor of Economics], \\ University of Michigan, 611 Tappan Street, Ann Arbor, Michigan 48109; baileymj@umich.edu; \\ Phone: (734) 647-6874. \\ Olga Malkova [Assistant Professor of Economics], \\ University of Kentucky, Gatton College of Business and Economics, Lexington, KY, 40502; \\ o.malkova@uky.edu.
}

\section{Zoë M. McLaren [Assistant Professor of Health Management and Policy]}

School of Public Health, University of Michigan, 1415 Washington Heights, M3166, Ann Arbor, Michigan 48109-2029; zmclaren@umich.edu.

\begin{abstract}
This paper examines the relationship between parents' access to family planning and the economic resources of their children. Using the county-level introduction of U.S. family planning programs between 1964 and 1973, we find that children born after programs began had 2.8\% higher household incomes. They were also $7 \%$ less likely to live in poverty and $12 \%$ less likely to live in households receiving public assistance. A bounding exercise suggests that the direct effects of family planning programs on parents' resources account for roughly two-thirds of these gains.
\end{abstract}

We have a growing concern to foster the integrity of the family and the opportunity for each child. It is essential that all families have access to information and services that will allow freedom to choose the number and spacing of their children.

$\sim$ President Lyndon Johnson, Special Message to the Congress on Domestic Health and Education, March 1, 1966.

...I called for a national commitment to provide a healthful and stimulating environment for all children during their first five years of life. One of the ways in which we can promote that goal is to provide assistance for more parents in effectively planning their families....Unwanted or untimely childbearing is one of several forces which are driving many families into poverty or keeping them in that condition.

\footnotetext{
Data Replication:
}

The data used in this article are available after a formal application to Census and can be used only in Research Data Centers (https:// www.census.gov/about/adrm/fsrdc/about/available_data.html).

All online appendixes can be found at http://jhr.uwpress.org/. 
$\sim$ President Richard Nixon, Special Message to the Congress on Problems of Population Growth, July 18, 1969.

A growing body of literature shows that early childhood and family characteristics are important determinants of lifetime health, earnings, and well-being (Almond and Currie 2011). Household income in childhood is one of the strongest correlates of completed education and adult health (Case, Lubotsky, and Paxson 2002; Almond and Currie 2011). There are many potential reasons for this relationship: Poor children receive less parental time and fewer resources. They are more likely to experience health and academic problems, live in more dangerous neighborhoods, attend underperforming schools, and be incarcerated (Guryan, Hurst, and Kearney 2008; Levine and Zimmerman 2010). Poor children ultimately have lower academic test scores (Reardon 2011), lower rates of high school and college completion (Bailey and Dynarski 2011), and lower earnings in adulthood (Pew Charitable Trusts 2012).

This cycle of disadvantage is the target of a variety of public policies and programs that aim to reduce gaps in early childhood resources and improve children's lifetime outcomes (Currie and Rossin-Slater 2015). Programs such as the Temporary Assistance for Needy Families (TANF) and the Earned Income Tax Credit (EITC) directly raised the household incomes of poor children at costs of around $\$ 10$ and $\$ 63$ billion in 2013, respectively. Medicaid and the State Children's Health Insurance Plan (S-CHIP) contributed roughly $\$ 444$ billion for children's health insurance in 2013. Head Start provided $\$ 8$ billion for preschool programs for around 930,000 disadvantaged children in 2014.

This paper evaluates the relatively less studied impact of family planning programs on childhood disadvantage. Although largely absent from today's policy discussions of childhood disadvantage, family planning programs have been considered a means to improve children's lives since at least the 1960s (Johnson 1966; Nixon 1969). Economic theory predicts that family planning programs could directly impact children's opportunities by increasing the incomes of their parents. This direct "resource effect" would result if family planning programs reduce the cost of avoiding unintended pregnancies, which constrain parents' choices when they occur and even when they do not occur (because they influence parents' expectations and, therefore, discourage their investments). By reducing the cost of avoiding unintended pregnancies, family planning programs may encourage parents' investments in their human capital, partnerships, and careers (Goldin and Katz 2002; Bailey 2006; Hock 2008; Christensen 2011; Bailey, Hershbein, and Miller 2012). With standard assumptions about the income elasticity of child quality, a rise in income should itself serve to increase investment in each child and should be reinforced by the substitution effect (Becker and Lewis 1973; Willis 1973). To this point, empirical evidence shows that wanted children tend to have better health at birth (Corman and Grossman 1985; Grossman and Joyce 1990; Gruber, Levine, and Staiger 1999) and to be treated better by their parents (David, Dytrych, and Matejcek 2003, David 2006).

This paper provides novel evidence on the resource effect of family planning programs on children's economic resources. Our research design exploits the roll-out of federally funded family planning programs between 1964 and 1973 within a dynamic, event-study framework 
(Bailey 2012). Using the restricted-use long-form 1970 and 1980 Census samples, we compare the outcomes of children in the same county born before and after federally funded family planning programs began. We find that cohorts born after programs began were significantly more economically advantaged. They lived in households with 2.8 percent higher annual incomes; they were 7 percent less likely to live in poverty; and they were 12 percent less likely to live in households receiving public assistance. These changes were driven in part by older mothers reducing unwanted pregnancies. As a result, the average child born after family planning programs began was slightly more likely to live in a twoparent family, have a younger mother, and have fewer older siblings.

Understanding the role of "selection" in driving these findings is crucial for their interpretation. If these gains in the outcomes of the average child reflect reductions in childbearing among disadvantaged parents, this selection effect could raise the income of the average child (because the poorest children are missing) even without increasing the resources available to any child that is born. The quantitative importance of selection may be large, because the federally funded family planning programs increased contraceptive use more among economically disadvantaged women (Jaffe, Dryfoos, and Corey 1973; Torres and Forrest 1985). ${ }^{1}$ If, on the other hand, family planning programs directly increase the household incomes of the average child (e.g., by encouraging investments in parental human capital, careers, and partnerships), our estimates imply a sizable and understudied role of family planning programs as an anti-poverty program. ${ }^{2}$

A bounding exercise informs our understanding of the contribution of selection to our findings. If selection follows the same income distribution as the distribution of incomes of family planning users, the exercise suggests that selection accounts for around 36 percent of the total increase in the income of the average child. That is, family planning programs directly raised incomes available to children by around $\$ 1,200$ per year in 2013 dollars (the remaining 64 percent of the rise in children's average incomes). Taking into account the uncertainty in these estimates, the lower confidence interval on the resource effect can explain at least 16 percent of the estimated gains, or $\$ 300$ per year.

This finding underscores an important and understudied return to family planning programs: they appear to directly raise parents' income by allowing them to invest in their own human capital and careers and find stable partnerships. This implies that a large share of the substantial education and labor-market gains to the children of mothers with access to family planning programs (documented in Bailey 2013) may be explained by the program's direct impact on their parents. Accounting only for the effects on child poverty, the resource effect of family planning programs may reduce child poverty in the U.S. at around half of the cost of the EITC and one-quarter of the cost of TANF. Because higher household incomes also increase investment in children's human capital, these estimates suggest that the long-term

\footnotetext{
${ }^{1}$ Family planning programs in the period we study were not means tested, but more affluent women tended to use other sources of care. A related literature suggests the potential importance of abortion legalization via the selection effect is large in both the short run (Gruber, Levine, and Staiger 1999) and the longer run (Pop-Eleches 2006; Ananat et al. 2009).

${ }^{2}$ A large literature studies the relationship of childbearing to child welfare. Schultz (2008) provides a thorough review of these studies in the context of developing countries. A much smaller literature studies the relationship of family planning programs and children's outcomes. See Miller and Babiarz (2015) for a review of these studies for middle- and low-income countries. Section II of our paper also reviews related studies of abortion legalization in the U.S.
} 
effects of family planning programs on children's economic opportunities may be even greater.

\section{A HISTORY OF U.S. FAMILY PLANNING PROGRAMS AND THEIR EXPECTED EFFECTS ON CHILDREN'S OUTCOMES}

The architects of President Lyndon B. Johnson's War on Poverty viewed the price of reliable contraceptives as a barrier to reducing poverty and promoting children's economic wellbeing. Of particular concern was that the Pill, the first oral contraceptive, was prohibitively costly in the 1960s. An annual supply of oral contraception sold for the equivalent of $\$ 812$ in 2013 dollars (Bailey 2013) — roughly twice today's annual cost and equivalent to more than three weeks of full-time work at the 1960 minimum wage (without factoring in the cost of visiting a physician). Numerous studies documented at the time that poor women were less likely to use effective contraceptives. We calculate in the 1965 National Fertility Study (NFS), for instance, that poor women were 44 percent $(0.082$ percentage points $/ 0.185$, s.e. 0.023 ) less likely to use the Pill than more affluent women. They also had roughly 0.60 (s.e. 0.16) more children on average than families with higher incomes.

To reduce disparities in access to contraception, the Office of Economic Opportunity (OEO) began funding family planning programs as early as 1964 . OEO grants rose to roughly $\$ 427$ million (2013) by 1970 and supported the opening of new clinics in disadvantaged areas and, to a lesser extent, the expansion of existing family planning programs. In November 1970, Congress passed Title X of the Public Health Service Act (also known as the Family Planning Services and Population Research Act, P.L. 91-572). By 1974, this legislation had increased federal support by 50 percent in real terms over 1970 levels. (See Bailey 2012 and Bailey 2013 for a detailed history of these programs and federal funding.)

The aim of these programs was to bring education, counseling, and the provision of low-cost contraceptives and related medical services to disadvantaged women. Family planning grants did not fund abortion, which was illegal before 1970 except in special circumstances. And, even after abortion was legalized in several states and nationally in 1973, Title X explicitly prohibited the use of federal funds "in programs where abortion is a method of family planning” (\$1008). During these early years, little is known about these programs' day-to-day operations. The federal government did not collect information on their services or patients, and officials talked very little about them-perhaps because topics like birth control were taboo. ${ }^{3}$ This dearth of evidence limits detailed exploration of the mechanisms of our estimated effects. To the extent that family planning programs varied in their implementation, the effects we estimate will represent the weighted combination of many services and types of programs, all of which provided reduced-cost contraceptives and related services.

${ }^{3}$ Levitan (1969: 209) writes that, "Contrary to the usual OEO tactic of trying to secure the maximum feasible visibility for all its activities, the OEO prohibited [family planning] grantees from using program funds to 'announce or promote through mass media the availability of the family planning program funded by this grant." Before 1965, U.S. federal involvement and investments in family planning had been modest. 
Between 1964 and 1973, federally funded family planning programs were established across the U.S., providing the identifying variation for this study.

Figure 1 shows the roll-out of these family planning programs at the county level. The counties with the earliest programs, established between 1964 and 1967, are shaded in red; the counties with programs established between 1968 and 1969, during the expansion of family planning as a national emphasis program, are orange; and the counties with programs established from 1970 to 1973, under Title X, are green. By 1973, federal funding had initiated or substantially expanded over 660 family planning programs across all of the lower 48 states. These programs funded services in locations where roughly 56 percent of the U.S. population of women ages 15 to 44 lived.

\section{A. The Impact of Federal Programs on Use of Family Planning Services and Fertility Rates}

Between 1969 and 1984, the number of family planning patients at federally funded programs grew 400 percent (Torres and Forrest 1985: 284), but no previous study has documented how much of this increase in the use of services was caused by federal funds. To the extent that patients of federally funded family planning programs had received services elsewhere or paid for services themselves, this 400 percent increase will overstate the impact of federal programs on the use of family planning services.

Two new data sources uniquely allow this paper to describe the effect of federal funding on the use of family planning services and the birth control pill. The first is a series of OEO reports. These reports supply information on the use of family planning services by county as reported by all known providers (hospitals, health departments, and clinics operated by other agencies) (OEO 1969; OEO 1971; OEO 1974). ${ }^{4}$ We use these data to estimate a differences-in-differences specification, where we code the first year a county receives a federal grant as the "treatment" dummy. ${ }^{5}$ Panel A of

Table 1 shows that federal family planning programs significantly increased the use of family planning services among women counted as "medically indigent" (i.e., those who could not afford care). The share of family planning patients served at all locations who were deemed medically indigent by the provider increased by around 2.7 percentage points after the federal family planning programs began. These estimates are robust to the inclusion

\footnotetext{
${ }^{4}$ Completion rates of the survey were high. In 1968, for example, 97 percent of hospitals and 100 percent of all other agencies responded (OEO 1969, table 3: 244). The purpose of the survey was to approximate the universe of potential family planning providers for our period of interest and document the number of "medically indigent" patients. This term was defined by the OEO to mean those who could not afford care due to lack of income but they did not recommend a specific income threshold. The definition, therefore, likely varied across providers.

${ }^{5}$ We estimate $Y_{j, t}=\theta_{j}+\gamma_{s(j), t}+\tau 1\left(t>T_{j}^{*}\right)+\boldsymbol{X}_{j, t}^{\prime} \boldsymbol{\beta}+\varepsilon_{j, t}$ where $Y_{y, t}$ is the share of medically indigent patients in county $j$ using family planning services from any provider (federally funded or not) in year $t$ (FY 1968, CY 1969, and FY 1971), $\theta_{j}$ is a set of county fixed effects, $\gamma_{S}(j), t$ is a set of state-time fixed effects, and $\boldsymbol{X}$ is a set of covariates including REIS controls and 1960 county covariates interacted with a linear trend. The binary indicator, $1\left(t>T_{j}^{*}\right)$, is equal to 1 for observations in years after the date county $j$ received its first federal family planning grant, $T_{j}^{*}$. The point estimate of interest, $\tau$, captures the differential change in the share of medically indigent women using family planning services after federal family planning programs were established. With the inclusion of county fixed effects, only counties receiving federal programs between 1968 and 1971 identify $\tau$.
} 
of additional covariates (cols. 1 to 3 ) and about half the magnitude of the national increase in family planning program use over the same period.

The second data source is the 1970 NFS. This survey sampled ever-married women between the ages of 18 and 44 and provides an alternative perspective from the point of view of individuals. We estimate a probit model to examine whether respondents living in counties with a federal family planning program before 1970 were more likely to have used the Pill by the time of the survey. We also examine whether the expected increase in Pill use was larger among poorer women. ${ }^{6}$ The estimates show that poor women in areas that had federal family planning programs by 1970 were much more likely to have used the Pill relative to poor women in areas receiving programs after 1970, an increase of around 23 to 30 percent (13 to 17 percentage points) over the mean for poor women (

Table 1, panel B). This effect of receiving a federal family planning program is large enough to erase income-based differentials in Pill use. ${ }^{7}$ The sparseness of these data limits strong conclusions, but both analyses suggest that federal programs increased the use of family planning services by a sizable amount. ${ }^{8}$

As a result, these programs also decreased childbearing. ${ }^{9}$ In work closely related to this study, Bailey (2012) exploits the county-level roll-out of federal family planning programs between 1964 and 1973 as a natural experiment to quantify their fertility effects. The idea behind using the program roll-out is that this timing approximates the conditional random assignment to greater access to family planning services. Using an unweighted, event-study specification and county-level Vital Statistics data on births from 1959 to 1988, she shows that fertility rates fell by 2 percent within 5 years after federal family planning programs began and remained approximately 1.7 percent lower up to 15 years later (see Bailey 2012, Table 2). Supporting the validity of her research design, Bailey (2012) found pre-period differences between eventually funded counties and never-funded counties were not statistically different from zero, but that post-period effects were robust to the inclusion of county and year fixed effects, state-by-year fixed effects, and a variety of time-varying county-level covariates. ${ }^{10}$

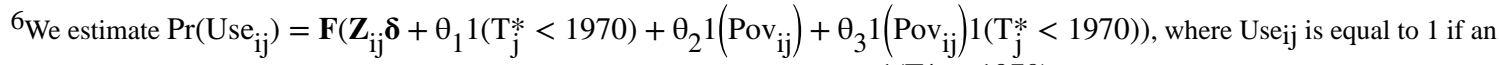
individual $i$ in county $j$ had ever used family planning or the birth control pill, $1\left(\mathrm{~T}_{\mathrm{j}}^{*}<1970\right)$ is a binary variable equal to one if county $j$ received a federal family planning grant before the survey date, and $1\left(\operatorname{Pov}_{i j}\right)$ is a binary variable equal to 1 if the annual household income in 1970 fell below the poverty line. County fixed effects cannot be included with this single cross-section, but we include a rich set of covariates, Z, including state fixed effects, dummy variables for age, educational achievement, population size of the county, and Catholic religion. In addition, one specification includes dummy variables for the "number of children most desirable" to capture residual, unaccounted-for differences in the demand for children. Panel B of Table 1 reports average partial effects associated with $\theta_{1}$ and $\theta_{3}$ from a probit and bootstrapped standard errors (1000 replications) and capture differences in the use of family planning services and the Pill in funded counties by 1970 .

${ }^{7}$ Another interesting finding is that Pill use increased by about 4 percentage points for women above the poverty line in funded locations. This estimate is not statistically significant but suggests family planning grants may have reduced the price of the Pill among women using other sources of family planning.

${ }^{8}$ The OEO reports were collected at only four points in time, and the 1970 NFS do not have complete coverage of all counties or time periods and exclude never married women.

${ }^{9}$ Reductions in childbearing likely reflect both reductions the number of wanted and unwanted births and change the desired timing of childbirth (Michael and Willis 1976).

${ }^{10}$ A related study by Kearney and Levine (2009) of the more recent period exploits state-level variation in Medicaid eligibility for family planning among the near poor within a differences-in-differences framework. This study finds that greater eligibility for services in 17 states significantly reduced birth rates among teens (by 4 percent) and among older women (by 2 percent) within a few years.
} 
Bailey (2012) also provides other evidence to support the internal validity of this natural experiment. ${ }^{11}$ First, oral histories and interviews note that the OEO funding for family planning programs (and other programs) was not well targeted or organized. Robert Levine (1970) sums up the situation saying, "It was an era of great administrative confusion." Second, quantitative evidence supports the conditional random assignment assumption. Aside from urbanicity, 1960 county characteristics found to predict the roll-out of other War on Poverty programs fail to predict the initiation of federal family planning programs. Moreover, neither 1964 fertility rates nor 1960 to 1964 changes in fertility rates are correlated with the initiation of federal family planning programs. This means that applicants were not more likely to apply for programs and that administrators were not more likely to prioritize funding programs based on differentially high (or low) fertility rates.

Third, Bailey (2012) found that reproductive and contraceptive attitudes and behaviors in the 1965 NFS are uncorrelated with the initiation of federal family planning programs. These include pro-natalist attitudes, contraceptive use and behaviors, and family background characteristics correlated with the number of children. In addition to examining these outcomes individually, we also follow Kling, Liebman, and Katz (2007) and create a summary index of equally weighted average z-scores for these outcomes-a technique that serves to improve the statistical power to detect correlations that move in a common direction. Neither approach finds evidence that the establishment of federal family planning programs is related to these outcomes individually or when combined in an index (coefficient: 0.054, robust standard error: 0.047, observations: 2,857). ${ }^{12}$

A final piece of evidence shows that the initiation of federal family planning programs is uncorrelated with the initiation of other War on Poverty programs, including community health centers, Head Start programs, jobs programs, legal services programs, and programs for maternal and infant care. In short, the qualitative and quantitative evidence is consistent with the assumption that federal family planning programs were conditionally, randomly assigned to U.S. counties.

\section{THE EXPECTED EFFECTS OF FAMILY PLANNING PROGRAMS ON THE ECONOMIC RESOURCES OF CHILDREN}

The increased availability of family planning services could affect the economic and living circumstances of children through two main channels. The first is what we call the resource effect and the second is the selection effect.

The resource effect refers to the situation in which family planning directly raises the incomes of parents. This would be the case if soon-to-be parents could use family planning services to delay childbearing in order to get more education, pursue different career paths, or obtain different amounts of work experience and job training. In addition, women are

\footnotetext{
${ }^{11}$ For the interested reader, some of this evidence is summarized in Online Appendix A.

${ }^{12}$ This z-score index excludes age at first pregnancy and age at first Pill use. Including the age at first pregnancy (which implicitly omits women who never became pregnant), we find that the year of the first federal grant to family planning is positively but insignificantly related to the index (coefficient: 0.043 , robust standard error: 0.054 , observations: 2,607 ). We exclude age at first Pill use (appendix Table A1, col. 6) because it is often missing in the NSF data and inclusion severely limits our sample size.
} 
more likely to make different investments in their careers or stay attached to a job if they expect to be able to control future childbearing. If family planning programs allow older women to time births better, they could raise the labor-force participation of mothers, which could have large effects on household incomes of children once they are born. ${ }^{13}$

Evidence regarding the existence of this resource effect comes from the literature on legal access to the birth control pill for younger women. Using variation in state laws regulating the age of consent for (mostly) unmarried teens (Bailey et al. 2011; Guldi 2011), this literature shows that access to the Pill affected marital and birth timing and had lasting effects on women's and men's career investments. With earlier legal access to the Pill, women and men were more likely to enroll in and complete college (Hock 2008; Bailey, Hershbein, and Miller 2012), and women were more likely to work for pay, invest in on-thejob training, and pursue non-traditional professional occupations (Goldin and Katz 2002; Bailey 2006; Bailey, Hershbein, and Miller 2012) - investments that resulted in higher wages for women later in adulthood (Bailey, Hershbein, and Miller 2012). Ananat and Hungerman (2012) additionally show that access to contraception at younger ages improved the economic resources of children born to these women, although they provide no evidence on whether these gains accrued due to selection or the resource effect. ${ }^{14}$

Family planning's resource effect may also act through partnership decisions. For instance, family planning programs could reduce the price of delaying marriage (Goldin and Katz 2002) and improve spouse matching and reduce marital stress, thereby reducing subsequent divorce rates (Christensen 2011; Rotz 2016). If family planning programs increase the likelihood that parents remain together after a child is born, this will also serve to increase the economic resources available to children. ${ }^{15}$

The alternative to the resource effect is the selection effect. Selection refers to the channel through which family planning programs impact children's circumstances by altering who becomes a parent. This shift in the composition of parents could improve the living circumstances of the average child even in the absence of any direct effect on parental income. For instance, if fewer children are born to lower income parents, the resources of the average child could rise even though the incomes of any child that is born would not.

Selection may be a particularly important channel in explaining these programs' effects on children because programs in the 1960s disproportionately served poorer households.

Roughly 83 percent of program patients had incomes below 150 percent of the poverty line, and 13 percent were recipients of Aid to Families with Dependent Children (AFDC, the principal cash welfare program at the time) (Jaffe, Dryfoos, and Corey 1973, Torres and Forrest 1985: 284).

\footnotetext{
${ }^{13}$ On the other hand, parents may decide to have children earlier in their careers if subsequent births are more easily avoided, which could reduce the incomes of children in the short run but not necessarily in the long run.

${ }^{14}$ Some studies, however, show that women who became mothers in their teens (relative to teens who miscarried) had higher subsequent levels of employment and earnings (Hotz, McElroy, and Sanders 2005).

${ }^{15}$ Akerlof, Yellen, and Katz (1996) suggest an alternative model in which family planning programs reduce the cost of non-marital sex and, therefore, increase non-marital childbearing. If non-marital childbearing increases, this should tend to lower household incomes of the average child.
} 
Separating the resource and selection effects in cross-sectional, retrospective data is impossible to do directly, because the two effects appear identical. Notably, although studies quantifying the impact of legal abortion on children's outcomes in the U.S. attribute all of the gains to selection, these findings could also partially reflect a resource effect. Analyzing the staggered legalization of first-trimester abortion in the U.S., initially in five states around 1970 and then in the remainder of states after Roe v. Wade in 1973, these studies show that birth rates fell by 4 to 8 percent (Levine et al. 1996) and that the outcomes for cohorts born after abortion was legalized improved. Gruber, Levine, and Staiger (1999) show that children born after abortion legalization were less likely to die as infants, live with single parents or in families receiving welfare, and live in poverty. Ananat et al. (2009) find that, later in life, these children were more likely to graduate from college, less likely to rely on welfare, and less likely to be single parents. Donohue and Levitt (2001) show that cohorts born after abortion legalization were less likely to commit crime, ${ }^{16}$ and Charles and Stephens (2006) show that these cohorts were less likely to use controlled substances in their late teens. One study of Romania explicitly considers the role of selection. When Romania experienced the reverse policy change-the prohibition of abortion, Pop-Eleches (2006) shows that birth rates among the most educated mothers (who had been using abortion and family planning services) increased by around 30 percent. After accounting for this positive selection of mothers, however, the paper shows that these unintended children fared worse in terms of their later socioeconomic outcomes.

In summary, the availability of family planning programs may increase family resources of both younger and older parents. In addition, family planning programs may also affect children's measured outcomes by altering selection into parenthood. Bailey's (2013) findings that family planning programs improved adult outcomes are consistent with both channels: either increases in parents' incomes or changes in selection (or a combination of both) could explain the higher college completion rates and the 2 percent increase in income for the average adult child. Understanding the quantitative importance of the resource and selection channels is, therefore, crucial to interpreting these estimates. The next section describes this study's empirical strategy to estimate these combined effects and bound the role of selection to recover an estimate of the direct effect of family planning programs on parents' incomes (e.g., the resource effect).

\section{RESEARCH DESIGN AND DATA}

The restricted, long-form samples of the 1970 and 1980 Censuses provide information on children's economic resources and living circumstances. In addition to their large sample sizes (20-percent and 16-percent samples of the U.S. population for 1970 and 1980, respectively), these samples identify county of residence (information that is suppressed in public samples). ${ }^{17}$ Our analysis aggregates the economic resources and living circumstances of children under age 18 into birth-year/county cohorts. ${ }^{18}$ These birth-year/county cohorts

\footnotetext{
${ }^{16}$ Claims that abortion reduced crime are disputed (Donohue and Levitt 2004; Joyce 2004; Dills and Miron 2006; Foote and Goetz 2008).

${ }_{17}$ Public Census samples identify county groups (which change between 1970 and 1980) and are much smaller. Restricted data are available after a formal application to Census and can be used only in Research Data Centers.

${ }^{18}$ Birth year is constructed using age and quarter of birth at the time of the Census.
} 
are then linked to information on when their county first established a federally funded family planning program. ${ }^{19}$

Our primary specification exploits variation in the timing of the first federal family planning grants to identify these programs' effects. In practice, our event-study framework contrasts the evolution of outcomes for cohorts born after family planning programs were first established in the county to those born before, and allows adjustments for a variety of potentially confounding factors:

$$
Y_{j, t}=\theta_{j}+\gamma_{s(j), t}+\sum_{c=a}^{b} \tau_{c} 1\left(t-T_{j}^{*}=c\right)+\boldsymbol{X}_{j t}^{\prime} \boldsymbol{\beta}+\varepsilon_{j, t},
$$

where $Y$ is a measure of the outcomes for children residing in county $j$ within state $s$ and born in calendar year $t$. 1( ) indexes birth cohorts relative to the year of the first federal family planning grant, $T_{j}{ }^{*}$ - the year the program started. ${ }^{20}$ We run separate regressions using the 1970 and 1980 Censuses in order to recover the regression-adjusted evolution of children's outcomes for cohorts born from six years before and up to six years after each county received its first federal family planning grant for a balanced set of counties. In our analysis, event time, $c$, runs from a years before up to $b$ years after the date of the first family planning grant, where the 1970 Census covers $a=-7$ through $b=1$, and the 1980 Census covers $a=-3$ through $b=7$. We do not pool the two Censuses because the 1970 data identify $\tau$ using only the 461 counties funded prior to 1970 , whereas the 1980 data identify $\tau$ in the full set of funded counties. Both Censuses, therefore, independently estimate event years -3 through 1, and using both Censuses allows us to estimate $\tau$ using a balanced set of counties for the greatest range of event time. ${ }^{21}$

Our baseline specification includes $\theta$, a set of county fixed effects that capture time-invariant county-level differences, a set of birth-year fixed effects, and $\gamma$, and a set of state-by-birth year fixed effects that capture time-varying changes in state policies, including abortion legalization and the roll-out of Medicaid. We present unweighted results (Solon, Haider, and Wooldridge 2015). Standard errors are robust to heteroskedasticity and corrected for serial correlation within state (Arellano 1987; Bertrand, Duflo, and Mullainathan 2004).

The robustness of these baseline results are examined by sequentially including covariates used in other studies of War on Poverty programs. Covariates include annual information on

\footnotetext{
${ }^{19}$ These data come from the National Archives Records about Community Action Program Grants and Grantees, which contain information on OEO family planning programs, and the National Archives Federal Outlay files, which contain information on programs funded under Title X. Bailey (2012) describes these data in greater detail.

20 Data limitations (federal family planning grant information is missing for some years) make it impossible to use federal grant dollars as the independent variable of interest. But even if this was feasible, we prefer a binary measure of family planning access for several reasons. Using variation in federal funding could also be related to program performance, which could induce reverse causality and threaten the interpretation of our estimates. Second, as described in section I, federal dollars paid for infrastructure when needed and also many programs were heavily supported by other public and non-profit funds by the end of the period of interest. Thus, federal dollars are poor proxies of program size or intensity. Our specification captures the fact that federal dollars created or significantly expanded family planning programs.

${ }^{21}$ The 1980 Census only covers a two-year cohort pre-trend for a balanced set of counties because many of the individuals in cohorts born before 1963 had begun leaving home (and the earliest family planning programs began in 1965). Therefore, we set $a=-3$ when $c \leq 3$ and $b=7$ when $c \geq 7$, and event-years -2 through 6 are estimated using all funded counties for the 1980 Census. Using the 1970 Census, we set $a=-7$ when $c \leq 7$ and $b=1$ when $c \geq 1$, and event years -6 through 0 are estimated using all funded counties. $c=0$ is omitted in both cases to facilitate easy comparisons across Census years.
} 
per capita measures of government transfers from the Bureau of Economic Analysis Regional Economic Information System (REIS) (cash public assistance benefits such as Aid to Families with Dependent Children, Supplemental Security Income, and General Assistance; medical spending such as Medicare and military health care; and cash retirement and disability payments) (Almond and Currie 2011). In some specifications, we also include the number of abortion providers, which accounts for within-state changes in the provision of abortion between 1970 and 1979 (Bailey 2012). ${ }^{22}$

An important challenge to our analysis is that the Censuses contain information on a child's residence in (or five years before) the Census year-not residence at the time of the child's birth. If mothers move between the time of birth and observation in the Census, this could lead us to misclassify mothers' access to federal family planning programs around the time of conception. We take several steps to limit this mobility-induced misclassification. First, we use county of residence five years before the Census, because 1975 is more temporally proximate to the year of birth for cohorts of children identifying our parameters of interest (and, therefore, more strongly correlated with mother's exposure to federal family planning programs) than 1980; we use 1965 for the 1970 Census for consistency. Second, we exclude unfunded areas from our estimation sample, because of their differential mobility relative to funded areas after family planning programs started. Finally, we follow Card and Krueger (1992) to adjust for mobility using a post-estimation correction. ${ }^{23}$ (See Online Appendix B for a discussion and additional results related to corrections for mobility bias.)

\section{THE ESTIMATED EFFECTS OF FAMILY PLANNING PROGRAMS ON THE ECONOMIC RESOURCES OF CHILDREN}

We begin by examining the effects of family planning programs on the log household income of the average child born. Figure 2presents results from our baseline model, which includes county and state-by-birth-year fixed effects. Estimates to the left of the vertical axis represent cohorts born in event years before family planning programs began (1970 Census estimates plotted in dashed lines), and estimates to the right of the vertical axis capture cohorts born after family planning programs began (1980 Census, solid lines with markers). Dashed lines plot 95-percent, point-wise confidence intervals for this model. ${ }^{24}$

Consistent with the resource and the selection effects operating as expected, Figure 2 shows that cohorts born after federal family planning programs began had significantly higher

\footnotetext{
${ }^{22}$ The interactions of county covariates are identical to those in Almond, Hoynes and Schanzenbach (2011). Because information on abortion providers is not available at the county level before 1973, we follow Joyce, Tan, and Zhang (2013) in assuming the number of providers in 1970 to 1972 in states that legalized before Roe $v$. Wade is identical to the number observed in 1973.

${ }^{23}$ Card and Krueger (1992) note that the estimated coefficients affected by mobility, $\tau_{\mathcal{c}}$, are a reweighting of the true coefficients, $\tau_{j}^{*}$.

In our case, $\tau_{c}=\sum_{j=a}^{b} \tau_{j}^{*} \cdot p_{j, c}$, where $p_{j, c}$ is the probability of being born in a county treated with family planning $j$ years before birth conditional on living in a county at the time of the Census that was treated $c$ years before birth. We use the matrix form of the equation to recover the full set of estimates, $\boldsymbol{\tau}^{*}=\boldsymbol{\tau} \boldsymbol{P}^{\mathbf{- 1}} \cdot \boldsymbol{\tau}$ is a $(\mathrm{b}-\mathrm{a}+1) \times 1$ column vector containing each of the event-study coefficients, $\tau_{c}$ for $\mathrm{c}=\mathrm{a}, \mathrm{a}+1, \mathrm{a}+2 \ldots, \mathrm{b}$, and $\mathrm{P}$ is a $(\mathrm{b}-\mathrm{a}+1) \times(\mathrm{b}-\mathrm{a}+1)$ matrix with elements of the transition probabilities, $p_{j}$, such that $\boldsymbol{\tau}$ $=\boldsymbol{\tau} \boldsymbol{P}^{*} \boldsymbol{P}$. We estimate $p_{j}$, as the probability of living in a county in $1975 / 1965$ receiving a family planning program $\mathrm{j}$ years before a birth conditional on living in a county in 1980/1970 that received a family planning program c years before birth. This assumes that county-to-county misclassification of treatment status between 1975 and 1980 (or 1965 and 1970) is correlated with mobility induced misclassification that occurred before 1965/1975.

${ }^{24}$ For the interested reader, estimates for 1970 and additional robustness checks are presented in Online Appendix C.
} 
household incomes. Although the household income of birth cohorts was stable before family planning programs began, the introduction of family planning programs corresponds to a notable trend break. Table 2 demonstrates the robustness of these estimates to different control variables and mobility bias adjustments for the 1980 Census. Column 1 includes only county and year fixed effects, column 2 (our baseline model and preferred specification) adds 850 state-by-year fixed effects (50 states $* 17$ birth years), column 3 adds county-level covariates, column 4 adds controls for abortion providers, and column 5 adjusts our baseline model for mobility bias using Card and Krueger's (1992) post-estimation correction. Across specifications, cohorts born five years after the programs began had household incomes that were very similar-2.7 percent higher in our baseline specification (col. 2). Consistent with mobility attenuating our estimates, the Card and Krueger (1992) mobility correction raises the estimate modestly to 3.0 percent (col. 5). In contrast, the coefficients on household incomes among cohorts born up to six years before family planning programs began exhibit little trend and are not statistically different from the year the county received its first family planning program. ${ }^{25}$ Our baseline specification implies that the income of the average child was around $\$ 1,840$ higher $(\$ 68,000$ pre-program mean family income $\times 0.027$ ) among children born after family planning programs began. ${ }^{26}$

Because the restricted Census data are not top-coded, we also investigate the importance of outliers. Trimming the top and bottom 1 percent of children's household incomes, however, has little effect on these estimates. ${ }^{27}$ Another check using per-capita household income as a dependent variable shows that the effects are even stronger after taking account of the number of people in the household in 1980: the average child in cohorts born five years after the programs began had a statistically significant 3.5 percent higher per-capita household income (appendix table A5, col 2).

Increases in the income of the average child should be driven by households in the lower part of the income distribution. As noted previously, 83 percent of family planning patients had incomes below 150 percent of the poverty line. Consistent with this prediction,

Figure 3 and Table 3 present evidence of sharp reductions in measures of children's economic disadvantage. To simplify the interpretation of the coefficients,

Figure 3 plots estimates of $\tau$ divided by the pre-treatment mean dependent variable for both the 1970 and 1980 estimates. The series, therefore, denote changes in percent for each birth cohort indexed relative to the year the family planning program began. Table 3 presents estimates in levels and also summarizes the relevant pre-treatment means.

\footnotetext{
${ }^{25}$ Online appendices present all point estimates for the 1970 and 1980 Censuses, robustness checks, and the Card and Krueger (1992) correction for mobility. These sensitivity checks do not alter the conclusions presented here.

${ }^{26}$ This intention-to-treat estimate is not easy to rescale into a LATE (Imbens and Angrist 1994), because we do not have an estimate of the first stage. If we could measure a first stage, it would include use of new methods like the Pill (as in Table 1, panel B) as well as the more effective use of methods. Lapses in use or errors in use are an important cause of unintended pregnancy even today. Fortyone percent of unintended pregnancies occur among women who are using contraception in the month they become pregnant (Sonfield, Hasstedt, and Gold 2014). Effective use includes the continuity of use, which is not well measured in the NFS (or other modern fertility surveys).

${ }^{27}$ Trimming the top and bottom 1 percent of incomes somewhat reduces the magnitude of the estimate at year +6 but has a negligible effect on event years 4 and 5. One exception is event year -5 in 1970, where one child in a very small county came from an extremely affluent family. This single observation inflated the estimate at event year -5 by 30 percent in the full sample over the trimmed sample.
} 
The results show that cohorts born 5 years after federal family planning programs began were 7.4 percent less likely to live in poverty ( Figure 3A; Table 3, col. 1), 6.4 percent less likely to live below 1.5 times the poverty line (Table 3 , col. 2 ), and 4.3 percent less likely to live below 2 times the poverty line (Table 3, col. 3). As was the case with household income,

Figure 3A shows no evidence that these reductions reflect a pre-trend. These results are consistent with federal family planning programs having the largest effects on lower income women.

Administrative statistics also suggest that nonwhite women were overrepresented among family planning patients ( 30 percent of family planning patients versus only 17 percent of women of childbearing age). This suggests that the intention-to-treat effects of family planning might be larger among nonwhite children. Consistent with this prediction, Table 3 shows that the absolute reductions in poverty rates were two times larger for the average nonwhite child born 5 years after the program began $(-1.5$, s.e. 1.6) than for the average white child ( -0.8 , s.e. 0.6). Owing to smaller samples, the event study estimates for subgroups are imprecise. To increase precision, we summarize the event-study estimates in a standard differences-in-differences framework. Using a single dummy variable for the affected cohorts, we find that poverty rates among non-white children fell by a statistically significant 5.5 percent $(-2.0 / 34.8$, s.e. 0.81 , not reported in tables for brevity) over the first six years after family planning programs began. For white children, poverty rates fell by an insignificant 2 percent $(-0.28 / 14$, s.e. 0.29$)$. For nonwhite children, the effects of family planning programs are also generally larger for lower poverty thresholds, although imprecision limits strong conclusions about comparisons across thresholds.

Of course, reductions in child poverty could occur mechanically if family planning reduced the number of children in the household (which could lower the poverty threshold), even if household incomes did not change (i.e., the resource effect is zero). ${ }^{28} \mathrm{We}$, therefore, repeat our analysis by subtracting out the younger siblings that arrived after each child was born and then reconstruct poverty thresholds for each child at the time of birth. Notably, this lower threshold generates even larger reductions in poverty rates attributable to family planning, suggesting that subsequent births in the household reduced the estimated effects of family planning. This evidence foreshadows one of the paper's main conclusions that the resource effect plays an important role in explaining the improvement in children's living circumstances.

The introduction of family planning programs is also associated with a reduction in another measure of disadvantage: the share of children living in families receiving public assistance. Children born 5 years after family planning programs began were on average 12 percent less likely to live in households receiving public assistance (Figure 3B, Table 4, col. 1) than those born just before family planning programs began. While the magnitude of the coefficients suggests that the reductions mainly occurred among whites, the confidence intervals are too large to conclude that the effect of family planning on receiving public assistance differs by

\footnotetext{
${ }^{28}$ Consider a family of two earning $\$ 18,000$ in 2013 : they would not fall below the federal poverty line of $\$ 15,500$. But, having a child at the same annual income would put the same family below the federal poverty threshold of $\$ 19,530$ for a family of three.
} 
race. White cohorts born 5 years after family planning programs began were 10 percent less likely to live in households receiving public assistance (Table 4, col. 2). Although a greater share of non-white children lived in households receiving public assistance, the event-study estimates for nonwhite children are much less precise and noisier, exhibiting positive- to negative-signed coefficients (col. 3).

A final measure of children's disadvantage is living in a household with a single head. Nonmarital childbearing and single headship rose dramatically in the 1960s and 1970s (McLanahan and Watson 2011; Bailey, Guldi, and Hershbein 2014), and both trends have served to increase child poverty over the longer-term. If family planning programs encouraged these trends by reducing the cost of non-marital sex, they could have increased non-marital childbearing (Akerlof, Yellen, and Katz 1996). On the other hand, family planning programs could have dampened the longer-term increase in non-marital childbearing due to the reduced unwanted pregnancies among less committed couples.

Figure 3C shows evidence of the latter. Following the introduction of family planning programs, the share of children born to single heads decreased. Although the 95-percent confidence intervals in Figure 3C (Table 4, col. 4) include zero, a one-sided test rejects the hypothesis that the introduction of family planning programs increased the share of children living with single parents. As in the case of public assistance, these patterns are less noisy and more precisely estimated for white children relative to nonwhite children (Table 4, cols. 5 and 6). To investigate this result further, we conduct a complementary analysis of countylevel Vital Statistics for marriage and divorce. Using marriages and divorces per woman ages 15 to 44 as the dependent variables in the same specification (and replacing cohort with year), we fail to reject that marriage and divorce rates remained the same after the introduction of family planning programs (appendix Figure A4).

Two final analyses help explain how family planning programs affected these outcomes. Using both the age of mothers at the time of each birth and the number of each child's older siblings (a measure of each child's birth order ${ }^{29}$ ) as dependent variables, we find that age of the average child's mother fell by around 0.3 years by year 5 , a reduction of 3.6 months (Table 5, col. 1). This finding is a weighted average of the effects of family planning programs on childbearing delay (which should increase the age of the average child's mother) and women ending their childbearing careers sooner (often called stopping, which should decrease the age of the average child). Although births to older women contribute relatively less to the overall birth rate than births to younger women, the potential reduction in age by avoiding an unwanted pregnancy in one's thirties is much larger ( 5 to 10 years on average) than the increase in age by delaying a pregnancy ( 1 to 3 years on average). On net, these opposing changes average out to a small negative number, suggesting that the shareweighted reduction in age was slightly larger than the share-weighted delay in birth.

The reduction in older siblings is also consistent with family planning programs helping older women avoid unplanned births. Children born 5 years after family planning programs

${ }^{29}$ We calculate the number of older siblings in the household at the time of each child's birth by subtracting out younger siblings from those present in the household. 
began had significantly fewer older siblings, implying that they were more likely to be lower-order births (first or second children rather than third or higher) (Table 5, col. 4). Evidence using changes in parity-specific birth rates reinforces this impression. Bailey (2012: Table 4B) shows that family planning programs did not affect first birth rates in the longer term (years 11 to 15), but they did reduce third-parity births for up to 15 years after they were established - a result consistent with family planning programs affecting stopping behavior. Changes in the living circumstances of the average child, therefore, appear to be driven largely by older mothers having fewer children. Because wages tend to increase with age, this makes the income and poverty results even more striking.

\section{A FRAMEWORK FOR BOUNDING THE IMPORTANCE OF SELECTION}

To what extent do improved living circumstances for children born after family planning programs began reflect the selection effect (i.e., reductions in childbearing among disadvantaged parents) or the resource effect (i.e., increased investments by parents in their own human capital, careers, and partnerships)? If only the selection effect operates, then the resources of the average child could rise even though the resources available to any one child do not. This section develops a novel framework for bounding the importance of selection, which allows us to approximate the resource effect. First, we show that empirical estimates of the overall effect of family planning programs can be decomposed into the sum of the selection effect and resource effect. Second, we use this decomposition to quantify the role of selection in raising the income of the average child.

Let $g(y) \geq 0$ represent the empirical distribution of the number of children across household income, $y$, before family planning programs began. We model income in discrete bins rather than as a continuous variable to match how it is reported in Census data and for simplicity of exposition. Summing over all households, $\sum_{y=0}^{\infty} g(y)=N$ is the total number of children and $\mu \equiv \frac{1}{N} \sum_{y=0}^{\infty} y g(y)$ is the household income of the average child. The introduction of a family planning program may change this average in two ways. First, selection may decrease the number of children that lower income families have. Let $g^{f p}(y) \geq 0$ capture the empirical distribution of the number of children by household income in the context of a family planning program. Note, $\sum_{y=0}^{\infty} g^{f p}(y)=M$, where $\mathrm{M}<\mathrm{N}$ and represents the number of children in all households after family planning programs. The inequality is strict because family planning programs strictly lower the number of children born. If family planning operated exclusively via the selection effect, then $\mu_{0}{ }^{f p} \equiv \frac{1}{M} \sum_{y=0}^{\infty} y g^{f p}(y)>\frac{1}{N} \sum_{y=0}^{\infty} y g(y) \equiv \mu$, as fewer children were born to lower income families. Second, family planning programs may directly raise the incomes of parents through the resource effect, which we capture as $h(y) \geq y$. This resource effect would further increase the income of the average child, such that $\mu_{1}{ }^{f p}=\frac{1}{M} \sum_{y=0}^{\infty} h(y) g^{f p}(h(y))>\mu_{0} f p>\mu$.

Our estimates, therefore, capture the treatment effects of family planning programs through both the resource and selection channels, which we can write as follows: 


$$
\tau^{f p} \equiv \mu_{1}^{f p}-\mu=\sum_{y=0}^{\infty}\left(\frac{1}{M} h(y) g^{f p}(h(y))-\frac{1}{N} y g(y)\right)
$$

By adding and subtracting a cross-term, we can decompose this effect into these two components, 30

$$
\begin{aligned}
\tau^{f p} & \\
& =\underbrace{\frac{1}{M} \sum h(y)\left[g^{f p}(h(y))-\frac{M}{N} g(h(y))\right]}_{\text {selection effect }} \\
& +\underbrace{\frac{1}{N} \sum g(y)[h(y)-y]+h(y)[g(h(y))-g(y)]}_{\text {resource effect }} .
\end{aligned}
$$

On one hand, if we assume family planning programs do not have a direct resource effect (i.e., $h(y)=y$ ), the second part of the expression (the resource effect) becomes zero and the treatment effect reflects solely selection. On the other hand, if we assume the selection effect is zero (i.e., $M=N$ and $g^{f} p()=g()$ ), the treatment effect reflects only the resource effect.

We cannot estimate the selection effect directly. Instead, we use this equation to simulate the role of selection and then bound the resource effect. Our approach uses the 1960 Census data and family planning user characteristics from the 1970 NFS. We simulate two types of selection: (1) "lower truncation," which assumes that missing births were at the bottom of the income distribution, and (2) "likely selection," which assumes missing births followed the observed empirical distribution of the users of family planning services.

Table 6 presents the results from the bounding exercise. Because, as shown in the first row of the table, the exercise assumes the selection effect is zero; by construction, the resource effect explains the entirety of the estimated 2.75 percent increase in children's household income (unweighted average of effects for cohorts born 4 to 6 years after family planning, col. 2 of Table 2). To simulate lower truncation, we drop the poorest 2 percent of children from the 1960 Census, which corresponds to Bailey's (2012) estimates of the effect of family planning programs on fertility rates. ${ }^{31}$ This approach assumes that only the poorest parents use family planning programs to avert births. ${ }^{32}$ We simulate likely selection by assuming that missing births followed the empirical distribution of household income for the

\footnotetext{
${ }^{30}$ We obtain this result by adding and subtracting $\frac{1}{N} g(y) h(y)$ and $\frac{1}{N} g(h(y)) h(y)$. This approach is standard in decompositions, the weighting of the selection and resource effects will vary with the choice of this cross-term.

${ }^{31}$ We restrict our sample to the average age of children born 4 to 6 years after family planning programs started in our 1960 sample (ages 5 to 7) of funded counties. This results in truncation of children with household incomes on average below \$3442 in 2013 dollars annually in the 1959 distribution of children's household income. These estimates correspond to Bailey's (2012) weighted estimates averaged over event years 4 to 6 in Figure 6A and unweighted estimates, model 3, in Figure 6B.

${ }^{32}$ The general equation for selection can be written as, $\tau^{S} \equiv \mu^{S}-\mu=\frac{1}{M} \sum y\left[g f p(y)-\frac{M}{N} g(y)\right]$. For the case of lower truncation, $\mu^{s}=\frac{1}{M} \sum_{y>T} y g(y)$ where the mean captures the household income of the average child after removing all children below income $\mathrm{T}$, the truncation point.
} 
users of family planning services. We fit a log normal distribution to the household incomes reported by family planning patients in the 1970 NFS, which results in a distribution centered at the poverty line for a family of four ( $\$ 23,636$ annually in 2013 dollars in the 1960 Census) and a standard deviation corresponding to one-quarter of the standard deviation in the household incomes. We then remove a random 2 percent of children from the 1960 Census sample of children ages 5 to 7 from this distribution so that the household income of the missing children corresponds to the household income distribution of users of family planning programs. The result is that 81.4 percent of averted children come from households with incomes below 150 percent of the poverty line, which matches the poverty rate of family planning program users in administrative data ( 83 percent).

Table 6, rows 2 and 3, simulate the resource effects under lower truncation and empirically likely selection. The 95-percent confidence intervals for the estimates are generated using a nonparametric bootstrap procedure (Johnston and DiNardo 1997). ${ }^{33}$ Selection by truncation generates a 1.84 percent increase in household income, accounting for around 67 percent (1.84/2.75) of the increase in income of the average child, while the resource effect accounts for around 33 percent. The largest effect of selection (implied by its upper confidence interval of 2.0) suggests that selection can explain at most 72 percent of the gains. If we also account for the uncertainty in the estimate of the increase in income, however, we fail to reject that the resource effect could be zero and that the most extreme form of selection explains the entire increase in household income.

Likely selection can explain around 36 percent (1 percentage point) of the estimated increase in income of the average child. Our best estimate of the magnitude of the resource effect is that it accounts for the remaining 64 percent (1.75/2.75) of the increase in child income. Taking account of the uncertainty in the estimate of the increase in income as well as the simulated effect of selection, the lower 95-percent confidence interval on the resource effect implies that it accounts for at least 16 percent of the income gains to the average child. In short, the simulation rejects that the resource effect is zero under likely selection. This finding underscores an important and understudied return to family planning programs: they may directly raise parents' income by encouraging parents to invest in their human capital, careers, and partnerships.

\section{FUNDING FAMILY PLANNING AS AN ANTI-POVERTY PROGRAM}

More than 50 years after the first federally funded family planning programs began in the United States, this paper provides new evidence that they increased children's economic resources and reduced child poverty. Using a validated research design and large restricteduse Census samples, we find that children born after the introduction of federal family planning programs were 7 percent less likely to live in poverty and 12 percent less likely to live in households receiving public assistance. A bounding exercise suggests that these increases in the income of the average child were achieved through the sizable increases in the incomes of disadvantaged parents—net of changes in selection. Our bounding exercise

\footnotetext{
${ }^{33}$ We generate 10,000,000 bootstrap draws of the pre- and simulated post-program household incomes of the average child who is age 5 to 7 using the 1960 Census and take their difference. The resulting $2.5^{\text {th }}$ and $97.5^{\text {th }}$ percentiles of the $10,000,000$ values of the difference represent the 95-percent confidence interval for the selection effect.
} 
using the distribution of incomes of family planning users shows that the direct effect of these programs on the incomes of parents accounts for around 64 percent of the income gains for the average child. Although our data do not allow us to establish the exact mechanisms for this effect, they are consistent with family planning programs reducing the constraints of unintended pregnancy and encouraging greater investments by parents in their human capital, careers, and partnerships. To the extent that there were spill-overs in services to nearby counties, that older siblings (who are part of our comparison group) benefitted, or that parents' geographic mobility obscures our ability to measure the true effects, our results may understate the resource effects of family planning programs on children's economic resources.

The magnitudes of these estimated effects of family planning programs on income square well with others in the literature. For instance, our bounding exercise suggests that family planning programs directly increased the income of the average child by $\$ 1,200(0.0275 \times$ the average pre-family planning mean family income of $\$ 68,000$ in 2013 dollars $\times$ share due to the resource effect of family planning net of selection, or 1.75/2.75). Using Bastian and Michelmore's (forthcoming) estimate that college completion rates should rise by 4.2 percent for every \$1,000 increase in EITC income, our findings imply that college completion of children born to parents with access to family planning should increase by around 5 percent. This estimate is similar to the findings in Bailey (2013), who shows that the combined income and selection effects of family planning programs raised children's likelihood of college graduation by 2 to 7 percent. ${ }^{34}$

The magnitudes of these estimates also imply that the returns to family planning programs compare favorably with other public policies aiming to increase the resources of disadvantaged children. In the 1960s the federal government spent an average of around $\$ 278$ million per year (2013 dollars) on family planning, or \$4.4 billion over 1964 to 1980 (the period considered in this analysis). Using our estimates of likely selection, family planning programs directly reduced child poverty by 1 percent for just under $\$ 1$ billion ( $\$ 4.4$ billion/( $7 * 0.64$ ), where 7 is the percent reduction in child poverty (Table 3 ) is and 0.64 the share of each point attributable to the resource effect (Table 6, row 3, likely selection).

Comparing the parental income returns (resource effects) of family planning programs to those of other programs targeting child poverty place these estimates in perspective. According to the supplemental poverty measure (SPM) for 2012, TANF cost $\$ 10.24$ billion in 2013 dollars and reduced child poverty rates by 2.7 percent (from 18.5 to 18.0 percent). Ignoring offsetting behavioral changes and deadweight loss, this implies that TANF reduced child poverty by 1 percent for every $\$ 3.8$ billion spent. Another useful comparison is the EITC. In 2012, the EITC cost around \$63 billion, and the 2012 SPM suggests that EITC and the refundable portion of the child tax credit reduced child poverty rates by 27 percent (from 24.7 to 18.0 percent). A similar calculation implies that EITC reduced child poverty by 1 percent for every $\$ 2.3$ billion spent. In short, even when we ignore the effect of family planning programs on public assistance outlays and through the selection channel, the

\footnotetext{
${ }^{34}$ Note that Bailey's (2013) findings may be affected by mobility from birth to adulthood.
} 
effects of family planning programs on parents' incomes reduced child poverty at less than half of the cost of the EITC and roughly one quarter of the cost of TANF. ${ }^{35}$

These resource effects may translate into large and long-term gains for children. For instance, Dahl and Lochner (2012) use variation in EITC eligibility over time and find a 4 to 6 percent of a standard deviation improvement in children's test scores for each $\$ 1,000$ of additional income. Milligan and Stabile's (2011) study of Canada's child benefit programs and Chetty, Friedman, and Rockoff's (2014) study of U.S. tax credits find comparable estimates. Aizer and Currie (2014) show that children receiving a 12 to 25 percent increase in household income through the mother's pension program in the early 20th century went on to attain about 0.4 years more schooling, had healthier weights in adulthood, earned about 14 percent more as adults, and lived about one year longer. Consistent with this, Bailey (2013) provides suggestive evidence from public Census data that cohorts born after family planning programs began were 2 percent more likely to attain 16 or more years of education and had 1 percent higher family incomes as adults (see Schultz 2008 for a discussion of developing countries). Future work should investigate these longer-run linkages as well as the intergenerational impact of family planning programs on the economy.

\title{
Supplementary Material
}

Refer to Web version on PubMed Central for supplementary material.

\section{Acknowledgements:}

\begin{abstract}
We gratefully acknowledge the use of the services and facilities of the Population Studies Center at the University of Michigan (funded by NICHD Center Grant R24 HD041028). During work on this project, Olga Malkova was supported by the NICHD (T32 HD0007339) as a UM Population Studies Center Trainee. The collection of data on U.S. family planning programs was supported by the University of Michigan's National Poverty Center (NPC) and Robert Wood Johnson Health and Society Programs; the University of Michigan Population Studies Research Center's Eva Mueller Award; the National Institutes of Health (HD058065-01A1 and HD070950-02); the University of Kentucky Center for Poverty Research (UKCPR) through the U.S. Department of Health and Human Services, Office of the Assistant Secretary for Planning and Evaluation (5 UO1 PE000002-05). Work on various aspects of this project was generously supported by the Small Grants Program at the University of Michigan's National Poverty Center, the University of California-Davis Center for Poverty Research (1H79AE000100-1 from the U.S. Department of Health and Human Services, Office of the Assistant Secretary for Planning and Analysis, which was awarded by the Substance Abuse and Mental Health Services Administration), and the Elizabeth Caroline Crosby Fund and Rackham Graduate School at the University of Michigan. The opinions and conclusions expressed herein are solely those of the author and should not be construed as representing the opinions or policy of any of these funders or any agency of the federal government or the U.S. Census Bureau. All results have been reviewed to ensure that no confidential information is disclosed. We are grateful to Doug Almond, Hillary Hoynes and Diane Schanzenbach for sharing the 1959 to 1978 Regional Economic Information System (REIS) data and to the Guttmacher Institute and Ted Joyce for sharing information on abortion providers from 1973 to 1979 . We are grateful to Maggie Levenstein and Clint Carter for assisting with the restricted data application and disclosure from Michigan's RDC. We benefited from comments and insights on early versions of this paper from Marianne Bitler, John DiNardo, Melanie Guldi, Maria Fitzpatrick, Brad Hershbein, Hilary Hoynes, David Lam, Doug Miller, and Gary Solon. Andrew Covert, Anna Erickson, Johannes Norling, and Annie Wentz provided outstanding research assistance.
\end{abstract}

35 Accounting for behavioral changes, the effects of TANF and EITC will differ (Hoynes, Miller, and Simon 2015). 


\section{VII.References}

Aizer Anna, and Currie Janet. 2014 "The Intergenerational Transmission of Inequality: Maternal Disadvantage and Health at Birth.” Science 344(6186): 856-861. [PubMed: 24855261]

Akerlof George, Yellen Janet, and Katz Michael L.. 1996 “An Analysis of out-of-Wedlock Childbearing in the United States." Quarterly Journal of Economics 111(2): 277-317.

Almond Douglas, and Currie Janet. 2011 "Human Capital Development before Age Five." Handbook of Labor Economics 4: 1315-1486.

Almond Douglas, Hoynes Hilary W., and Schanzenbach Diane W.. 2011 "Inside the War on Poverty: The Impact of Food Stamps on Birth Outcomes.” Review of Economics and Statistics 93(2): 387403.

Ananat Elizabeth O., Gruber Jonathan, Levine Phillip B., and Staiger Doug. 2009 “Abortion and Selection." Review of Economics and Statistics 91(1): 124-136.

Ananat Elizabeth O., and Hungerman Daniel. 2012 "The Power of the Pill for the Next Generation: Oral Contraception's Effects on Fertility, Abortion, and Maternal and Child Characteristics." Review of Economics and Statistics 94(1): 37-51. [PubMed: 22389533]

Arellano Manuel. 1987 “Computing Robust Standard Errors for Within-Groups Estimators.” Oxford Bulletin of Economics and Statistics 49(4): 431-434.

Bailey Martha J. 2013 "Fifty Years of Family Planning: New Evidence on the Long-Run Effects of Increasing Access to Contraception.” NBER Working Paper 19493.

Bailey Martha J. 2006 "More Power to the Pill: The Impact of Contraceptive Freedom on Women's Lifecycle Labor Supply.” Quarterly Journal of Economics 121(1): 289-320.

Bailey Martha J. 2012 "Reexamining the Impact of U.S. Family Planning Programs on Fertility: Evidence from the War on Poverty and the Early Years of Title X." American Economic Journal: Applied Economics 4(2): 62-97. [PubMed: 22582135]

Bailey Martha J., and Dynarski Susan. 2011 “Inequality in Postsecondary Education” In Whither Opportunity? Rising Inequality and the Uncertain Life Chances of Low-Income Children, ed. Duncan Greg J. and Murnane Richard J., 117-132. New York, NY: Russell Sage.

Bailey Martha J., Guldi Melanie, Davido Allison, and Buzuvis Erin. 2011 "Laws and Policies Governing Contraceptive Access, 1960-1980.” Unpublished. Retrieved August 1, 2011 Available at http://www-personal.umich.edu/ baileymj/ELA_laws.pdf.

Bailey Martha J., Guldi Melanie, and Hershbein Brad J.. 2014 "Is There a Case for a "Second Demographic Transition": Three Distinctive Features of the Post-1960 U.S. Fertility Decline" Human Capital and History: The American Record, ed. Boustan Leah Platt, Frydman Carola and Margo Robert A., 273-312, Cambridge, MA: National Bureau of Economics Research.

Bailey Martha. J., Hershbein Brad J., and Miller Amalia R.. 2012 “The Opt-in Revolution? Contraception and the Gender Gap in Wages.” American Economic Journal: Applied Economics 4(3): 225-254. [PubMed: 23785566]

Bastian Jacob, and Michelmore Katherine. 2016 "The Long-Term Impact of the Earned Income Tax Credit on Children's Education and Employment Outcomes." Journal of Labor Economics. Forthcoming

Becker Gary S., and Lewis H. Gregg. 1973 "On the Interaction between the Quantity and Quality of Children.” Journal of Political Economy 81(2): S279-S288.

Bertrand Marianne, Duflo Esther, and Mullainathan Sendhil. 2004 "How Much Should We Trust Differences-in-Differences Estimates?” Quarterly Journal of Economics 119(1): 249-275.

Card David, and Krueger Alan B.. 1992 "Does School Quality Matter? Returns to Education and the Characteristics of Public Schools in the United States.” Journal of Political Economy 100(1): 140 .

Case Anne, Lubotsky Darren, and Paxson Christina. 2002 "Economic Status and Health in Childhood: The Origins of the Gradient.” American Economic Review 92(5): 1308-1334. [PubMed: 29058397]

Charles Kerwin Kofi, and Stephens Melvin Jr. 2006 “Abortion Legalization and Adolescent Substance Use.” Journal of Law and Economics 49(2): 481-505. 
Chetty Raj, Friedman John N., and Rockoff Jonah E.. 2014 "Measuring the Impacts of Teachers I: Evaluating Bias in Teacher Value-Added Estimates.” American Economic Review 104(9): 25932632.

Christensen Finn. 2011 "The Pill and Partnerships: The Impact of the Birth Control Pill on Cohabitation." Journal of Population Economics 25(1): 29-52.

Corman Hope, and Grossman Michael. 1985 "Determinants of Neonatal Mortality Rates in the U. S.: A Reduced Form Model.” Journal of Health Economics 4: 213-236. [PubMed: 10300553]

Currie Janet, and Rossin-Slater Maya. 2015 "Early-Life Origins of Life-Cycle Well-Being: Research and Policy Implications.” Journal of Policy Analysis and Management 34(1): 208-242. [PubMed: 25558491]

Dahl Gordon B., and Lochner Lance. 2012 "The Impact of Family Income on Child Achievement: Evidence from the Earned Income Tax Credit.” American Economic Review 102(5): 1927-1956.

David Henry P. 2006 "Born Unwanted, 35 Years Later: The Prague Study.” Reproductive Health Matters 14(27): 181-190. [PubMed: 16713893]

David Henry P., Dytrych Zdenek, and Matejcek Zdenek. 2003 "Born Unwanted: Observations from the Prague Study.” American Psychologist 58(3): 224-229. [PubMed: 12772429]

Dills Angela. K., and Miron Jeffrey. A.. 2006 “A Comment on Donohue and Levitt's (2006) Reply to Foote and Goetz (2005).” Retrieved June 3, 2018 Available at https://scholar.harvard.edu/files/ miron/files/comment_on_dl_fg_0.pdf.

Donohue John J., and Levitt Steven D.. 2004 "Further Evidence That Legalized Abortion Lowered Crime: A Reply to Joyce." Journal of Human Resources 39(1): 29-49.

Donohue John J., and Levitt Steven D.. 2001 “The Impact of Legalized Abortion on Crime.” Quarterly Journal of Economics 116(2): 379-420.

Foote Christopher L., and Goetz Christopher F.. 2008 "The Impact of Legalized Abortion on Crime: Comment." Quarterly Journal of Economics 123(1): 407-423.

Goldin Claudia, and Katz Lawrence F.. 2002 "The Power of the Pill: Oral Contraceptives and Women's Career and Marriage Decisions.” Journal of Political Economy 110(4): 730-770.

Grossman Michael, and Joyce Ted. 1990 "Unobservables, Pregnancy Resolutions, and Birth Weight Production Functions in New York City.” Journal of Political Economy 98(5): 983-1007.

Gruber Jonathan, Levine Phillip, and Staiger Douglas. 1999 “Abortion Legalization and Child Living Circumstances: Who Is the "Marginal Child"?" Quarterly Journal of Economics 114(1): 263-291.

Guldi Melanie. 2011 "A Survey of the Literature on Early Legal Access to the Birth Control Pill and its Influence on Young Women's Fertility, Education, Career, and Labor Supply" Research Handbook on the Economics of Family Law, ed. Cohen LR and Wright JD, 271-291. Northampton, MA: Edward Elgar.

Guryan Jonathan, Hurst Erik, and Kearney Melissa. 2008 "Parental Education and Parental Time with Children." Journal of Economic Perspectives 22(3): 23-46.

Hock Heinrich. 2008 "The Pill and the College Attainment of American Women and Men." Retrieved September 14, 2016 Available at ftp://econpapers.fsu.edu/RePEc/fsu/wpaper/wp2007_10_01.pdf.

Hotz V. Joseph, McElroy Susan W., and Sanders Seth G.. 2005 "Teenage Childbearing and Its Life Cycle Consequences: Exploiting a Natural Experiment.” Journal of Human Resources 40(3): 683715.

Hoynes Hilary W., Miller Doug, and Simon David. 2015 "Income, the Earned Income Tax Credit, and Infant Health.” American Economic Journal: Economic Policy 7(1): 172-211.

Imbens Guido W., and Angrist Joshua D.. 1994 "Identification and Estimation of Local Average Treatment Effects.” Econometrica 62(2): 467-475.

Jaffe Frederick S., Dryfoos Joy G., and Corey Marsha. 1973 “Organized Family Planning Programs in the United States: 1968-1972.” Family Planning Perspectives 5: 73-79. [PubMed: 4618203]

Johnson Lyndon B. 1966 Special Message to the Congress on Domestic Health and Education.

Johnston Jack, and DiNardo John E.. 1997 Econometric Methods. New York: McGraw-Hill.

Joyce Ted. 2004 “Did Legalized Abortion Lower Crime?” Journal of Human Resources 39(1): 1-28.

Joyce Ted, Tan Ruoding, and Zhang Yuxiu. 2013 “Abortion Before and After Roe.” Journal of Health Economics 32(5): 804-815. [PubMed: 23811233] 
Kearney Melissa S., and Levine Phillip. 2009 "Subsidized Contraception, Fertility, and Sexual Behavior." Review of Economics and Statistics 91(1): 137-151. [PubMed: 20130787]

Kling Jeffrey R., Liebman Jeffrey B., and Katz Lawrence F.. 2007 "Experimental Analysis of Neighborhood Effects." Econometrica 75(1): 83-119.

Levine Phillip, and Zimmerman David J.. 2010 Targeting Investments in Children: Fighting Poverty When Resources Are Limited. Chicago: University of Chicago Press.

Levine Phillip, Staiger Douglas, Kane Thomas, and Zimmerman David. 1996 "Roe V. Wade and American Fertility." NBER Working Paper 5615.

Levine Robert. 1970 The Poor Ye Need Not Have with You: Lessons from the War on Poverty. Cambridge: MIT Press.

Levitan Sar A. 1969 The Great Society's Poor Law: A New Approach to Poverty. Baltimore: Johns Hopkins Press.

McLanahan Sara, and Watson Tara. 2011 "Marriage Meets the Joneses: Relative Income, Identity, and Marital Status" Journal of Human Resources 46(3): 482-517. [PubMed: 24639593]

Michael Robert. T., and Willis Robert. J.. 1976 "Contraception and Fertility: Household Production Under Uncertainty" In Household Production and Consumption ed. Terleckyj Nestor E., 27-93. Cambridge, MA: National Bureau of Economic Research.

Miller Grant, and Babiarz Kimberly S.. 2015 "Family Planning: Program Effects" In International Encyclopedia of the Social and Behavioral Sciences, ed. Elo Irma and Foster A. Amsterdam: Elsevier.

Milligan Kevin, and Stabile Mark. 2011 "Do Child Tax Benefits Affect the Well-Being of Children? Evidence from Canadian Child Benefit Expansions." American Economic Journal: Economic Policy 3(3): 175-205.

Nixon Richard. 1969 Special Message to the Congress on Problems of Population Growth.

OEO. 1969 The Need for Subsidized Family Planning Services: United States, Each State and County, 1968.

OEO. 1971 The Need for Subsidized Family Planning Services: United States, Each State and County, 1969.

OEO. 1974 The Need for Subsidized Family Planning Services: United States, Each State and County, 1971.

Pew Charitable Trusts. 2012 "Pursuing the American Dream: Economic Mobility Across Generations.” Retrieved November 13, 2013 Available at http://www.pewtrusts.org/ /media/ legacy/uploadedfiles/wwwpewtrustsorg/reports/economic_mobility/ pursuingamericandreampdf.pdf

Pop-Eleches Christian. 2006 "The Impact of an Abortion Ban on Socioeconomic Outcomes of Children: Evidence from Romania.” Journal of Political Economy 114(4): 744-773.

Reardon Sean. 2011 "The Widening Academic Achievement Gap between the Rich and the Poor: New Evidence and Possible Explanations" In Whither Opportunity? Rising Inequality and the Uncertain Life Chances of Low-Income Children, ed. Duncan Greg J. and Murnane Richard J., 91-116. New York, NY: Russell Sage Foundation.

Rotz Dana. 2016 “Why Have Divorce Rates Fallen? The Role of Women's Age at Marriage.” Journal of Human Resources 51(4): 961-1002.

Schultz T. Paul. 2008 "Population Policies, Fertility, Women's Human Capital, and Child Quality” In Handbook of Development Economics, Volume 4, ed. Schultz TP and Strauss J, 3250-3303. Amsterdam, Netherlands: Elsevier.

Solon Gary, Haider Steven J., and Wooldridge Jeffrey M.. 2015 "What Are We Weighting For?" Journal of Human Resources 50(2): 301-316.

Sonfield Adam, Hasstedt Kinsey, and Gold Rachel Benson. 2014 "Moving Forward: Family Planning in the Era of Health Reform." Guttmacher Institute Retrieved January 26, 2017 Available at https:// www.guttmacher.org/sites/default/files/report_pdf/family-planning-and-health-reform.pdf.

Torres Aida, and Forrest JD. 1985 "Family Planning Clinic Services in the United States, 1983." Family Planning Perspectives 17(1): 30-35. [PubMed: 3979525] 
Willis Robert. J. 1973 “A New Approach to the Economic Theory of Fertility Behavior.” Journal of Political Economy 81(2): S14-S64. 


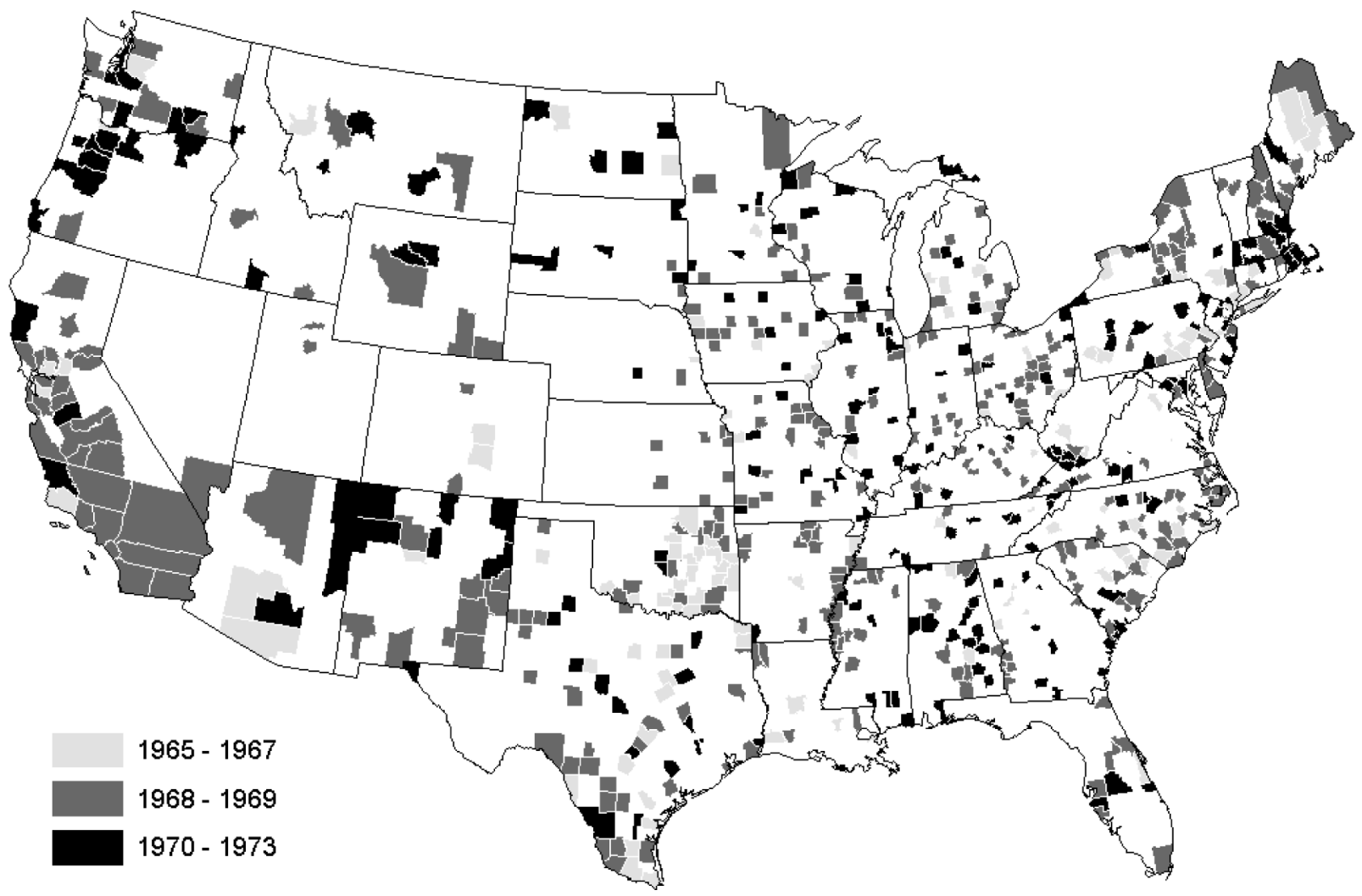

Figure 1. The Roll-Out of Federally Funded Family Planning Programs, 1965-1973

Dates are the year that the county first received a federal family planning grant. Counties not receiving a family planning grant between 1965 and 1973 are not shaded. 


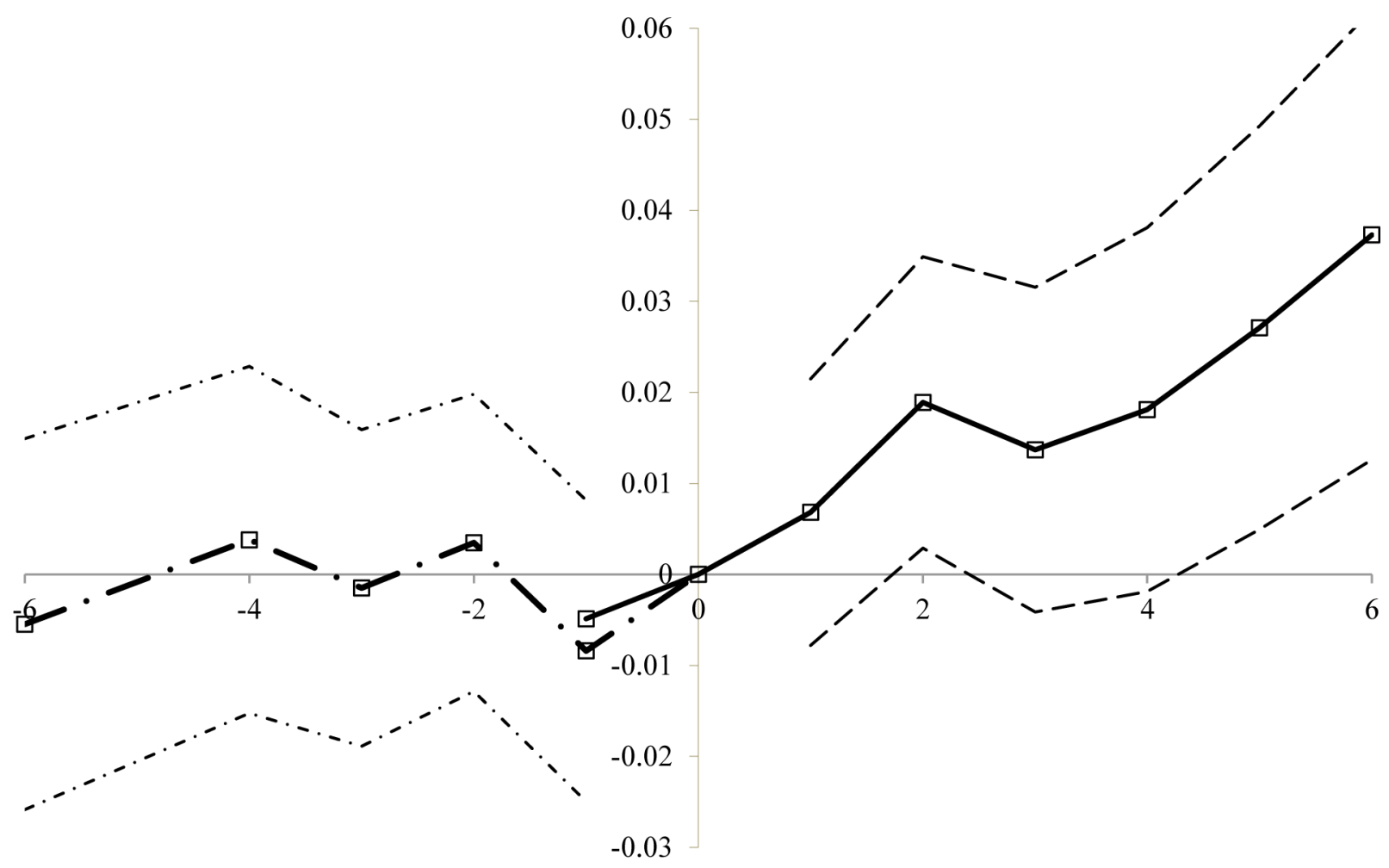

Figure 2. The Effect of Family Planning Programs on Log Household Income of the Average Child

The figure plots the percent change in household income (dependent variable) for children born up to 6 years before and up to 6 years after family planning programs began using the baseline model from estimating equation 1 (see also Table 2 and Table A4). The x-axis plots children's birth year relative to the year the county's family planning program started. As covariates, the baseline model includes county, birth year, and state by birth year fixed effects. Standard errors have been clustered by county and used to construct 95-percent, point-wise confidence intervals for the baseline model (dashed lines). Sources: 1970 (dashed lines with markers) and 1980 (solid lines with markers) restricted-use Censuses. 


\section{A. Percent Change in Children in Poverty}

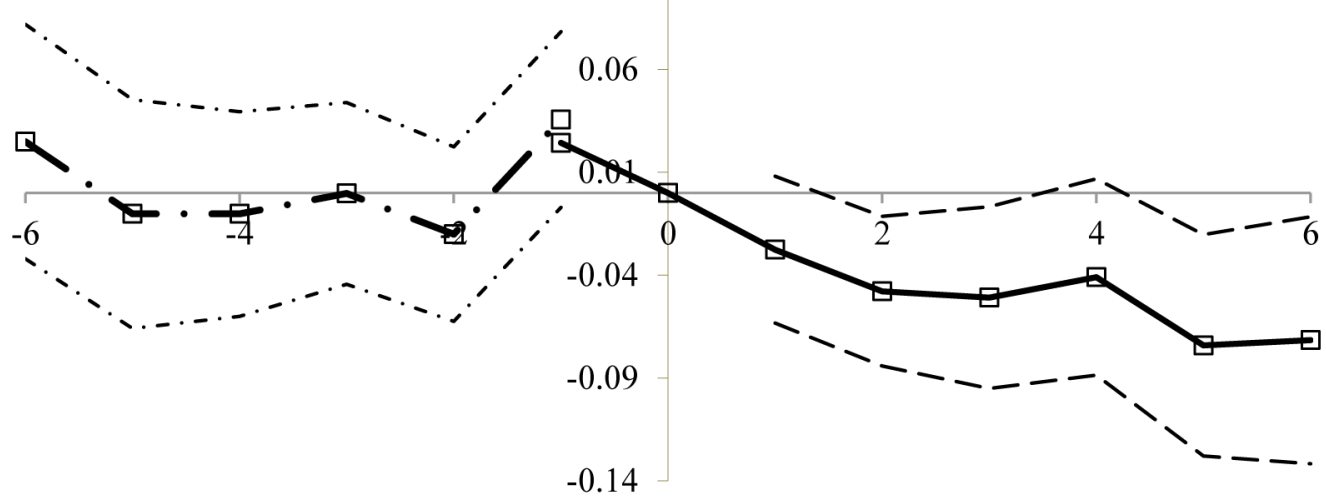

B. Percent Change in Children in Households Receiving Public Assistance
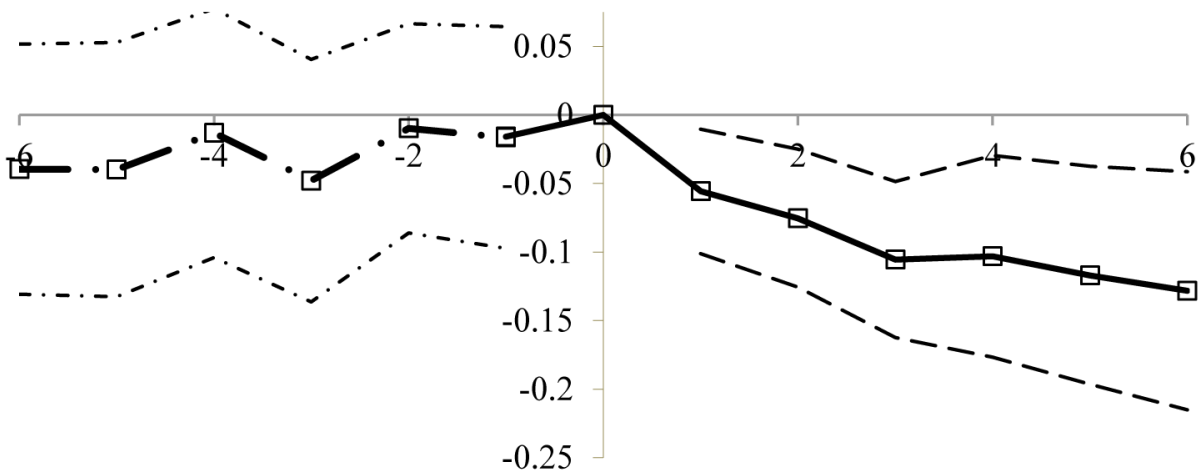

C. Percent Change in Children Living in Single-Parent Households
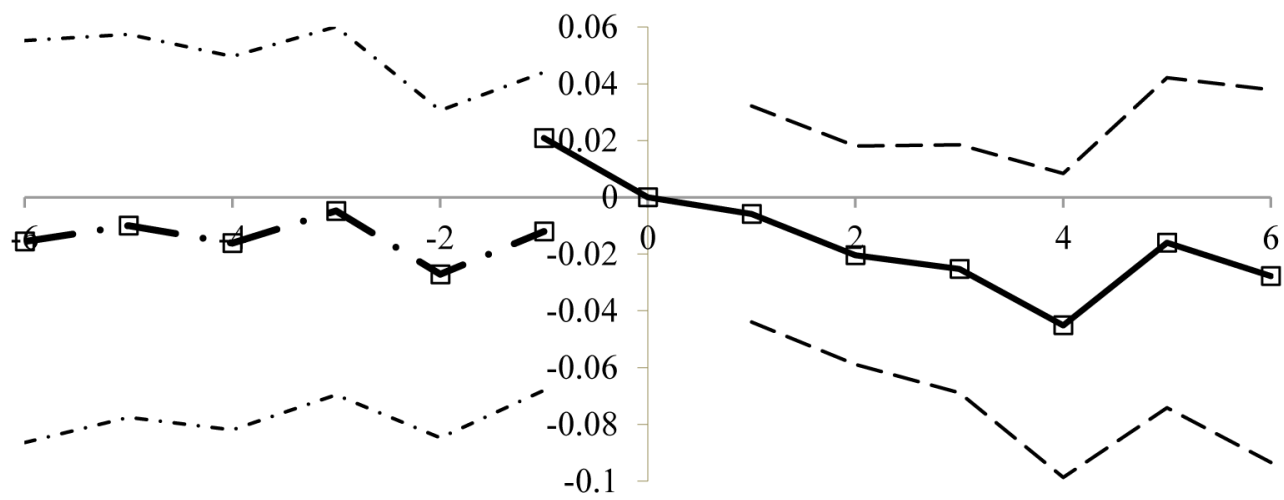

Figure 3. The Effect of Family Planning Programs on the Economic Disadvantage of the Average Child

Figure plots estimates of $\tau$ from estimating equation 1 divided by the pre-treatment mean dependent variable for both the 1970 and 1980 estimates. The series, therefore, denote changes in percent of children in a birth cohort with a given characteristics relative to the cohort born in the year the family planning program began. See also notes for Figure 2 and estimates in Table 3 and Tables A6, A9, A10. 
Table 1.

The Effect of Family Planning Programs on the Use of Services and the Pill

\begin{tabular}{|c|c|c|c|}
\hline & (1) & (2) & (3) \\
\hline & \multicolumn{3}{|c|}{$\begin{array}{l}\text { A. Dependent Variable: Share of Medically Indigent Patients Using Family Planning Services (1968 } \\
\text { Mean=0.046) }\end{array}$} \\
\hline \multirow[t]{2}{*}{ After family planning began } & 0.027 & 0.028 & 0.027 \\
\hline & {$[0.011]$} & {$[0.011]$} & [0.012] \\
\hline R-squared & 0.71 & 0.75 & 0.75 \\
\hline Counties & 666 & 666 & 666 \\
\hline Observations & 1998 & 1998 & 1998 \\
\hline \multirow[t]{2}{*}{ Covariates } & $\mathrm{C}, \mathrm{Y}$ & $\mathrm{C}, \mathrm{S}-\mathrm{Y}$ & $\mathrm{C}, \mathrm{S}-\mathrm{Y}, \mathrm{R}, \mathrm{X}$ \\
\hline & \multicolumn{3}{|c|}{ B. Dependent Variable: $1=$ Ever Used the Pill (Pre-treatment Mean $=0.56$ ) } \\
\hline \multirow[t]{2}{*}{ After family planning began } & 0.040 & -0.005 & -0.007 \\
\hline & {$[0.024]$} & {$[0.023]$} & {$[0.020]$} \\
\hline In Poverty & -0.165 & -0.160 & -0.179 \\
\hline (Mean $D V=0.58)$ & {$[0.084]$} & {$[0.075]$} & {$[0.073]$} \\
\hline After family planning began $\times$ & 0.166 & 0.132 & 0.146 \\
\hline In Poverty (Mean $D V=0.65)$ & {$[0.076]$} & {$[0.070]$} & {$[0.076]$} \\
\hline Pseudo R-squared & 0.026 & 0.157 & 0.165 \\
\hline Observations & 3699 & 3699 & 3681 \\
\hline State fixed effects & $\mathrm{X}$ & $\mathrm{X}$ & $\mathrm{X}$ \\
\hline Other covariates & & G,C,E,P & G,C,E,P,K \\
\hline
\end{tabular}

Panel A. The unit of observation is a county-year in FY1968, CY1969 and FY1971, and estimates are of $\tau$ from a restricted version of equation 1 (see text) using funded counties. Column 1 includes county, C, and year, Y, fixed effects. Column 2 adds state-by-year, S-Y, fixed effects. Column 3 adds 1960 county covariates interacted with a linear trend, X, and REIS controls, R. Heteroskedasticity-robust standard errors clustered by county are presented beneath each estimate in brackets. Sources: OEO 1969, 1971 and 1974.

Panel B: The unit of observation is a married woman ages 18 to 44 in 1970 . The estimates are average partial effects associated with $\theta_{1}$, $\theta_{2}$, and $\theta_{3}$ from a probit specification of a restricted form of equation 1 using funded counties. Bootstrapped standard errors (1000 replications) are reported in brackets beneath. Columns 1-3 include state fixed effects, column 2 adds dummy variables for age categories (G), Catholic (C), educational achievement (E), and the size of the primary sampling unit (P); and column 3 adds a set of dummy variables for the "ideal number of children" to proxy for other differences in the demand for children (K). Medically indigent: who could not afford care due to lack of income or insurance eligibility. Source: 1970 NFS. 
Table 2.

The Effect of Family Planning Programs on Log Household Income of the Average Child

\begin{tabular}{|c|c|c|c|c|c|}
\hline \multicolumn{6}{|c|}{$\begin{array}{c}\text { Dependent Variable: Log Household Income re-treatment mean of household income }{ }^{a} \text { : } \\
\$ \mathbf{\$ 6 8 , 0 0 0}\end{array}$} \\
\hline \multicolumn{6}{|c|}{ Event time: Cohort year of birth - year family planning program began } \\
\hline \multirow[t]{2}{*}{-2} & 0.004 & 0.001 & 0.001 & 0.001 & 0.002 \\
\hline & {$[0.00680]$} & [0.00747] & [0.00746] & {$[0.00747]$} & {$[0.00741]$} \\
\hline \multirow[t]{2}{*}{-1} & -0.001 & -0.005 & -0.005 & -0.005 & -0.006 \\
\hline & [0.00616] & {$[0.00665]$} & {$[0.00662]$} & {$[0.00663]$} & {$[0.00626]$} \\
\hline \multicolumn{6}{|l|}{$\begin{array}{r}0 \\
\text { (omitted) }\end{array}$} \\
\hline \multirow[t]{2}{*}{1} & 0.006 & 0.007 & 0.007 & 0.007 & 0.007 \\
\hline & [0.00691] & [0.00747] & [0.00748] & {$[0.00749]$} & [0.00732] \\
\hline \multirow[t]{2}{*}{2} & 0.016 & 0.019 & 0.019 & 0.019 & 0.021 \\
\hline & [0.00754] & [0.00817] & [0.00817] & [0.00818] & {$[0.00835]$} \\
\hline \multirow[t]{2}{*}{3} & 0.011 & 0.014 & 0.014 & 0.013 & 0.014 \\
\hline & [0.00807] & [0.00910] & [0.00911] & [0.00915] & [0.00946] \\
\hline \multirow[t]{2}{*}{4} & 0.015 & 0.018 & 0.018 & 0.018 & 0.019 \\
\hline & [0.00911] & [0.0102] & [0.0103] & [0.0103] & {$[0.0106]$} \\
\hline \multirow[t]{2}{*}{5} & 0.024 & 0.027 & 0.027 & 0.026 & 0.030 \\
\hline & [0.00996] & [0.0113] & [0.0115] & {$[0.0115]$} & {$[0.0118]$} \\
\hline \multirow[t]{2}{*}{6} & 0.033 & 0.037 & 0.037 & 0.036 & 0.043 \\
\hline & [0.0114] & {$[0.0126]$} & [0.0127] & {$[0.0128]$} & {$[0.0131]$} \\
\hline $\mathrm{R}$-squared & 0.345 & 0.413 & 0.414 & 0.414 & 0.413 \\
\hline \multirow[t]{2}{*}{ Covariates $b$} & $\mathrm{C}, \mathrm{Y}$ & $\mathrm{C}, \mathrm{Y}, \mathrm{S}-\mathrm{Y}$ & $\mathrm{C}, \mathrm{S}-\mathrm{Y}, \mathrm{R}$ & C, S-Y, R, & C, Y, S-Y, \\
\hline & & & & A & mobility adjusted \\
\hline $\begin{array}{l}\text { County } \times \text { birth year } \\
\text { cells } c\end{array}$ & 11313 & 11313 & 11313 & 11313 & 11313 \\
\hline Counties & 666 & 666 & 666 & 666 & 666 \\
\hline
\end{tabular}

The table presents point estimates of the change in log household income of children for cohorts born 2 years before and 6 years after family planning programs began. Coefficients are least-squares estimates of $t$ in equation 1 using the 1980 restricted-use Census data. See Online Appendix C for 1970 point estimates. Figure 2 plots event study estimates from the baseline model. Heteroskedasticity-robust standard errors clustered by county are in brackets.

${ }^{a}$ Pre-treatment mean in 1980 is the mean of the dependent variable in event years $t=0, t=-1$ and $t=-2$ in 2013 dollars.

${ }^{b}$ Covariate abbreviations are as follows: C and Y denote county and birth year fixed effects. S-Y denotes state-by-birth year fixed effects. R and A indicate REIS variables and abortion access measures. Column 5 includes estimates using baseline model (column 2) with Card and Krueger's (1992) post-estimation correction for mobility bias.

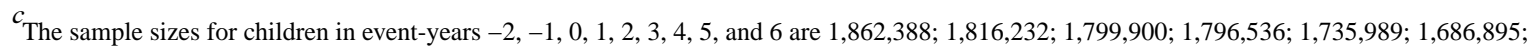
$1,636,621 ; 1,588,435$ and $1,560,401$, respectively. 


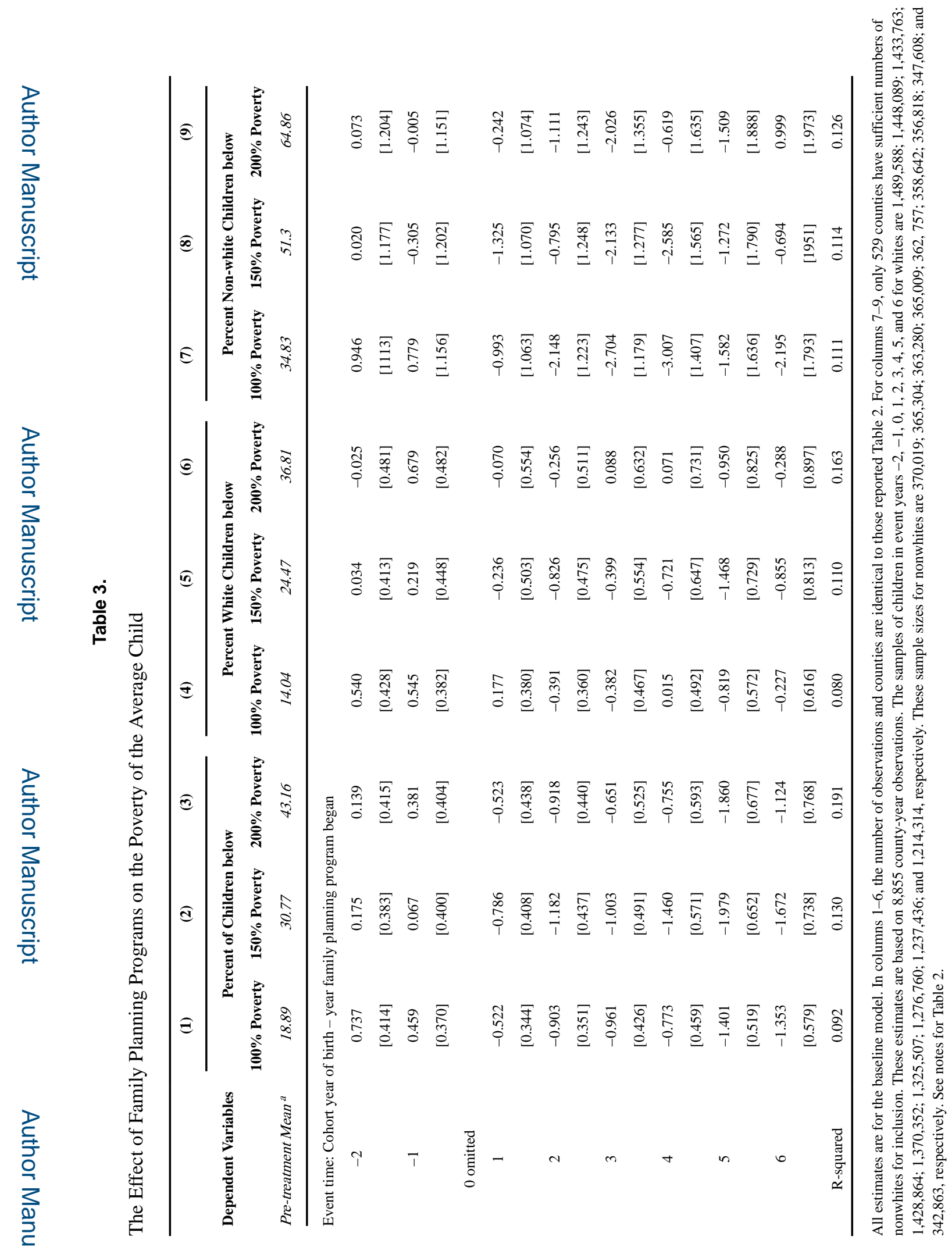

J Hum Resour. Author manuscript; available in PMC 2019 November 25. 
Table 4.

The Effect of Family Planning Programs on the Likelihood the Average Child Lives in a Household Receiving Public Assistance or Has a Single Parent

\begin{tabular}{|c|c|c|c|c|c|c|}
\hline \multirow{3}{*}{$\begin{array}{c}\text { Dependent Variables } \\
\text { Sample }\end{array}$} & (1) & (2) & (3) & (4) & (5) & (6) \\
\hline & \multicolumn{3}{|c|}{$\begin{array}{c}\text { Percent Children in Households Receiving Public } \\
\text { Assistance }\end{array}$} & \multicolumn{3}{|c|}{ Percent Children in Single Parent Households } \\
\hline & All & White & Non-white & All & White & Non-white \\
\hline Pre-treatment Mean ${ }^{a}$ & 11.4 & 7.7 & 24.8 & 17.4 & 13.4 & 35.0 \\
\hline \multicolumn{7}{|c|}{ Event time: Cohort year of birth - year family planning program began } \\
\hline-2 & -0.052 & -0.046 & -0.048 & -0.438 & -0.586 & 1.322 \\
\hline & [0.299] & {$[0.272]$} & [0.986] & {$[0.335]$} & [0.353] & [1.243] \\
\hline-1 & -0.180 & -0.016 & 0.343 & 0.363 & -0.109 & 1.588 \\
\hline & [0.282] & {$[0.251]$} & [1.099] & [0.349] & {$[0.362]$} & [1.139] \\
\hline \multicolumn{7}{|l|}{0 omitted } \\
\hline \multirow[t]{2}{*}{1} & -0.638 & -0.455 & 0.496 & -0.102 & -0.092 & 1.763 \\
\hline & {$[0.265]$} & [0.249] & [1.055] & {$[0.338]$} & [0.316] & [1.210] \\
\hline \multirow[t]{2}{*}{2} & -0.862 & -0.554 & -0.648 & -0.355 & -0.282 & 0.457 \\
\hline & [0.294] & {$[0.256]$} & [1.013] & {$[0.341]$} & {$[0.360]$} & [1.223] \\
\hline \multirow[t]{2}{*}{3} & -1.206 & -0.738 & -1.731 & -0.438 & -0.009 & -1.300 \\
\hline & [0.332] & [0.307] & [1.161] & [0.387] & [0.392] & [1.332] \\
\hline \multirow[t]{2}{*}{4} & -1.180 & -0.687 & 0.274 & -0.785 & -0.492 & -0.270 \\
\hline & [0.429] & [0.364] & [1.316] & {$[0.475]$} & {$[0.453]$} & [1.515] \\
\hline \multirow[t]{2}{*}{5} & -1.338 & -0.805 & -0.344 & -0.279 & -0.172 & 1.696 \\
\hline & {$[0.464]$} & [0.433] & [1.566] & [0.516] & [0.519] & [1.689] \\
\hline \multirow[t]{2}{*}{6} & -1.467 & -1.087 & 0.776 & -0.483 & -0.143 & 0.753 \\
\hline & {$[0.507]$} & [0.482] & [1.665] & {$[0.582]$} & {$[0.576]$} & [1.890] \\
\hline R-squared & 0.102 & 0.084 & 0.122 & 0.095 & 0.123 & 0.115 \\
\hline
\end{tabular}

See notes for Table 2 and 3. 
Table 5.

The Effect of Family Planning on the Age of Mother and the Number of Older Siblings of the Average Child

\begin{tabular}{|c|c|c|c|c|c|c|}
\hline \multirow{3}{*}{$\begin{array}{c}\text { Dependent Variables } \\
\text { Sample }\end{array}$} & (1) & (2) & (3) & (4) & (5) & (6) \\
\hline & \multicolumn{3}{|c|}{ Mother's Age at Birth } & \multicolumn{3}{|c|}{ Mean Number of Older Siblings } \\
\hline & All & White & Non-white & All & White & Non-white \\
\hline Pre-treatment Mean ${ }^{a}$ & 25.04 & 25.03 & 24.75 & 1.535 & 1.355 & 2.044 \\
\hline \multicolumn{7}{|c|}{ Event time: Cohort year of birth - year family planning program began } \\
\hline \multirow[t]{2}{*}{-2} & 0.045 & 0.083 & 0.206 & -0.020 & -0.016 & 0.047 \\
\hline & [0.0638] & [0.0675] & [0.190] & {$[0.0226]$} & [0.0225] & {$[0.0650]$} \\
\hline \multirow[t]{2}{*}{-1} & 0.078 & 0.070 & 0.526 & 0.013 & 0.007 & 0.085 \\
\hline & [0.0603] & [0.0649] & [0.173] & [0.0198] & [0.0192] & [0.0595] \\
\hline \multicolumn{7}{|l|}{0 omitted } \\
\hline \multirow[t]{2}{*}{1} & -0.003 & 0.010 & 0.335 & -0.017 & 0.004 & 0.037 \\
\hline & [0.0570] & [0.0612] & [0.170] & [0.0183] & [0.0187] & [0.0569] \\
\hline \multirow[t]{2}{*}{2} & -0.114 & -0.047 & 0.000 & -0.031 & -0.003 & -0.013 \\
\hline & {$[0.0652]$} & [0.0692] & [0.198] & {$[0.0191]$} & [0.0186] & {$[0.0570]$} \\
\hline \multirow[t]{2}{*}{3} & -0.182 & -0.132 & -0.099 & -0.038 & -0.009 & -0.035 \\
\hline & {$[0.0700]$} & [0.0767] & {$[0.220]$} & {$[0.0210]$} & [0.0208] & {$[0.0616]$} \\
\hline \multirow[t]{2}{*}{4} & -0.193 & -0.140 & 0.010 & -0.061 & -0.013 & -0.013 \\
\hline & [0.0859] & [0.0892] & [0.266] & {$[0.0271]$} & [0.0253] & [0.0818] \\
\hline \multirow[t]{2}{*}{5} & -0.303 & -0.220 & -0.252 & -0.069 & -0.015 & -0.122 \\
\hline & [0.0987] & [0.101] & [0.288] & [0.0297] & [0.0279] & [0.0842] \\
\hline \multirow[t]{2}{*}{6} & -0.276 & -0.173 & -0.497 & -0.064 & -0.012 & -0.115 \\
\hline & [0.104] & [0.111] & [0.293] & {$[0.0336]$} & [0.0303] & [0.0875] \\
\hline R-squared & 0.203 & 0.140 & 0.159 & 0.541 & 0.454 & 0.325 \\
\hline
\end{tabular}

See notes for Table 2 and Table 3. 
Table 6.

The Resource Effect of Family Planning under Different Assumptions about Selection

\begin{tabular}{lccc}
\hline & $(\mathbf{1})$ & $(\mathbf{2})$ & $(\mathbf{3})$ \\
& Simulated Selection Effect & Resulting Resource Effect & Share due to the Resource Effect \\
\hline No selection & -- & 2.75 & $100 \%$ \\
Selection by lower truncation & 1.84 & {$[1.46,4.04]$} & \\
& {$[1.69,2.00]$} & 0.91 & $33.1 \%$ \\
Empirically likely selection & 1.00 & {$[-0.39,2.21]$} & $63.6 \%$ \\
& {$[0.86,1.15]$} & 1.75 & \\
\hline
\end{tabular}

The results are very similar if we restrict the distribution of children's household incomes to be positive. The decomposition uses the cross-term in equation 4. The upper and lower 95-percent confidence intervals are below each effect in brackets. In row 1 the confidence interval is calculated using the standard error of the estimate. In rows 2 and 3 the confidence interval is calculated using the parametric bootstrap (Johnston and DiNardo 1997). Source: Authors calculations using the restricted 1960 Census. 